\title{
Issues and Potential Improvement of Multiband Models for Remotely Estimating Chlorophyll-a in Complex Inland Waters
}

\author{
Weining Zhu, Qian Yu, Yong Q. Tian, Brian L. Becker, and Hunter Carrick
}

\begin{abstract}
Remote estimation of chlorophyll-a (chl-a) in complex freshwaters remains a challenging problem due to the rapid spatial variability and wide range as influenced by terrestrial constituents. A controversial issue is whether or not 2-B models possess sufficient wavelength information for accurately estimating Chl-a concentrations from remote sensing data for freshwater environments. This study introduced a systemic approach and proved that adding additional wavelength information to 2 -B model could not significantly improve the estimation of freshwater chl-a, but acted to increase model uncertainty. This convincing solution was based on a large synthetic data set (38 937 samples) combined with a set of in situ data (51 samples) collected in three cruises in Lake Huron. The synthetic data set has two distinct features: 1) large data items and 2) covers a broad range of chl-a $\left(0-1000 \mathrm{mg} / \mathrm{m}^{3}\right)$, colored dissolved organic matter (CDOM) $\left(0-50 \mathrm{~m}^{-1}\right)$, and NAP (nonalgal particles) (0-500 mg/l). Additionally, this study reveals how hyperspectral wavelength selection, number of bands, bandwidth, and parameter calibration are associated with the uncertainty in remote sensing of chl-a. The systematic analysis approach was used to evaluate $34 \mathrm{chl}$-a algorithms by using optimal location and number of wavelengths as well as calibrated parameters. The study introduced a set of new 2-B, 3-B, and 4-B models derived also from using optimized parameters, suggested wavelengths, and bands available in MERIS and MODIS satellite images. Validation results demonstrated that these models are suitable to general freshwater environments because of broad ranges of biochemical and physical properties in both synthetic and in situ data.
\end{abstract}

Index Terms-Chlorophyll, coastal waters, model, remote sensing.

Manuscript received February 14, 2014; revised July 26, 2014; accepted September 23, 2014. Date of publication October 28, 2014; date of current version February 09, 2015. This work was supported in part by an internal grant from Central Michigan University Contribution No. 48 and in part by the two collaborative grants from the National Science Foundation under Grant 1025547 and Grant 1230261.

W. Zhu is with the Ocean College, Zhejiang University, Hangzhou 310058, China, also with the Institute for Great Lakes Research, Central Michigan University, Mt. Pleasant, MI 01003 USA, and also with the Department of Geography, Central Michigan University, Mt. Pleasant MI 48859 USA.

Q. Yu is with the Department of Geosciences, University of Massachusetts, Amherst, MA 48859 USA (e-mail: qyu@ geo.umass.edu).

Y. Q. Tian and B. L. Becker are with the Institute for Great Lakes Research, Central Michigan University, Mt. Pleasant, MI 48859 USA, and also with the Department of Geography, Central Michigan University, Mt. Pleasant, MI 48859 USA.

H. Carrick is with the Institute for Great Lakes Research, Central Michigan University, Mt. Pleasant, MI 48859 USA, and also with the Department of Biology, Central Michigan University, Mt. Pleasant, MI 48859 USA.

Color versions of one or more of the figures in this paper are available online at http://ieeexplore.ieee.org.

Digital Object Identifier 10.1109/JSTARS.2014.2360872

\section{INTRODUCTION}

A S THE MAJOR photosynthetic pigments of phytoplankton, chlorophyll plays a fundamental role in aquatic ecosystems. Estimation of chlorophyll using remote sensing is a key technique in the study of global/regional carbon cycles, calculations of aquatic plant biomass, evaluations of water quality, and studies centered on gaining a better understanding of human-climate interactions, etc. [1], [2]. Chlorophyll estimations in open oceans have been successful through the use of ocean color satellite sensors and blue/green band-ratio models [3], [4]. NASA routinely publishes global oceanic chlorophyll concentration distribution as SeaWiFS product using the well-known OCv4 algorithm [5].

Increasingly, algorithms and models developed for open sea waters are being applied to inland freshwaters, which are heavily influenced by their adjacent terrestrial environment and anthropogenic activities. Unfortunately, many studies have shown that open sea chlorophyll estimation models do not work well when applied to complex coastal and inland waters [6]-[10]. Freshwater chlorophyll estimation is challenging for three main reasons: 1) chlorophyll concentrations in inland aquatic environments could vary, from near zero to as high as $1600 \mathrm{mg} / \mathrm{m}^{3}$ [11]. 2) The presence of multiple types of chlorophyll (i.e., chl-a, chl-b, and chl-c) often contribute equally to what can be highly varied optical properties. 3) Two additional color components [i.e., colored dissolved organic matter (CDOM) and nonalgal particles (NAP)], are often in high concentrations and are highly visible [12], [13], which can severely interfere with the estimation of chlorophyll [14].

The most common chl-a algorithms are based on band-ratio models. The 2-B model suggests that chl-a concentration is proportional to a ratio of $\mathrm{B} 1 / \mathrm{B} 2$, where $\mathrm{B} 1$ and $\mathrm{B} 2$ typically fall within the blue and green bands/wavelengths for open-sea [3], [4]. It has been suggested that the two bands should fall within the NIR and red regions in turbid coastal/inland waters [7], [15], [16]. Alternatively, three-band semianalytical models [6], [17] usually incorporate one red (B1: 660-690 nm) and two NIR bands (B2: 710-730, and B3: $>730 \mathrm{~nm}$ ). The red B1 is usually set at a chl-a sensitive wavelength e.g., $667 \mathrm{~nm}$. B2 is effective in minimizing the influences of CDOM and NAP with the assumption that chl-a absorption is minimal in this wavelength domain. B3 was introduced to minimize the influence of particulate backscattering on reflectance. Recently, a 4-B model has also been proposed for removing the impact of high concentrations of sediments or elevated turbidity [18], [19]. 
4-B models usually include a fourth band within the NIR wavelength (e.g., 750-780 nm) in addition to the three bands found in 3-B models.

A controversial issue on the above band ratio algorithms is whether or not 2-B models possess sufficient wavelength information for accurately estimating chl-a concentrations from remote sensing data, especially comparing to 3-B/4-B models for freshwater environments. The controversial was mostly raised from case studies using two-, three-, and four-band ratio models. In theory, 3-B/4-B models should perform better than 2-B models do in general scenarios because of additional wavelength information. 2-B models incorporating a red and NIR band are most common relative to other model configurations (3-B and 4-B) for turbid inland waters. Dall'Omlo and Gitelson [21] reported in some cases, that the 2-B model slightly outperformed the 3-B model when using two band pairings: $\mathrm{B} 1=673 \mathrm{~nm}$ paired with $\mathrm{B} 3>730 \mathrm{~nm}$, or $\mathrm{B} 1=665 \mathrm{~nm}$ paired with $\mathrm{B} 3=705 \mathrm{~nm}$ [21]. This study also brought up another issue on what are the best wavelengths in 2-B model for general freshwater environment. Contrarily, some case studies [18] concluded that a 4-B model provided more accurate chl-a estimations than similarly configured 2-B and 3-B models in turbid waters. Recently, another case study by Gurlin et al., [29] showed that 2-B model outperformed 3-B/4-B models in estimating chl-a for turbid water. This unclear picture identified the need to improve our understanding of factors affecting chl-a estimation, such as optimal number of bands and the most appropriate wavelength domain by using large and identical synthetic and field data from representative freshwater environments.

Three shortcomings in current remote sensing of chl-a are: 1) limited/biased in situ data from case studies did not encapsulate enough variability to represent the inherent complexity of complex inland waters; 2) lack of a systematic approach for understanding the issues and potential improvements in the available 2-/3-/4-B models by using the same data set that has a wide range of chl-a concentrations; 3) neglect of band and parameter optimization strategies to determine a suitable model.

This paper addresses the three shortcomings mentioned above and introduced a systematic approach for solving the controversial in band ratio chl-a algorithms suitable to general freshwater environment. Our hypothesis is that adding additional wavelength information to 2-B model could not make significant improvement in estimating chl-a in freshwater environment, but acted to increase model uncertainty. We tested this hypothesis by using a large synthetic data set (38937 samples) combined with a set of in situ data (51 samples) collected in three cruises in Lake Huron. Two synthetic data sets generated via a Hydrolight two distinct features: 1) large data items and 2) covers a broad range of chl-a $\left(0-1000 \mathrm{mg} / \mathrm{m}^{3}\right)$, CDOM (0-50 $\left.\mathrm{m}^{-1}\right)$, and NAP $(0-500 \mathrm{mg} / \mathrm{l})$. The study reveals how hyperspectral wavelength selection, number of bands, bandwidth, and parameter calibration are associated with the uncertainty in remote sensing of chl-a by evaluating $34 \mathrm{chl}$-a algorithms. A most important outcome from this study is a set of new 2-B, 3-B, and 4-B models derived also from using optimized parameters and band selection. An independent set of synthetic and in situ data was used in validating that our new models are suitable to general freshwater environments because of broad ranges of biochemical and physical properties in both synthetic and in situ data.

\section{DATA AND Methods}

\section{A. Study Site and Field Measurements}

Three field measurements were conducted in the Saginaw and Kawkawlin River plume regions of Lake Huron, on May 10, October 18, 2012, and May 7, 2013. The Saginaw River $(36 \mathrm{~km})$ is the longest and highest volume river flowing into the Saginaw Bay of Lake Huron, while the Kawkawlin River is significantly smaller in length $(28 \mathrm{~km})$ and discharge. Their mouths enter into Saginaw Bay approximately $1 \mathrm{~km}$ apart (Fig. 1). Waters in the Saginaw River are typically turbid with a much heavier sediment load, while the Kawkawlin River generally discharges clearer but stained waters which appear much darker than the waters of Saginaw Bay. Detailed information of the study site could be found by referring to Zhu et al. [22].

Fifty-one surface water samples were collected, dispensed into amber bottles (polypropylene $500 \mathrm{ml}$ ), and stored in a cooler kept at ambient water temperatures for processing in the laboratory (within $6 \mathrm{~h}$ in Mount Pleasant, Michigan). The in situ water optical properties, including water leaving radiance $\left(L_{t}\right)$, sky radiance $\left(L_{i}\right)$, and downwelling irradiance $\left(E_{s}\right)$ were measured via a HyperSAS (hyperspectral surface acquisition system) and HyperOCR (hyperspectral ocean color radiometer) produced by Satlantic Inc. The measurements were taken from 10 A.M. to 2 P.M., under cloud free conditions and wind speeds of $\sim 4-10 \mathrm{~m} / \mathrm{s}$. The zenith and azimuth angles of the HyperSAS sensors were adjusted according to solar position. At each sampling point, $\sim 20$ spectral data were collected.

\section{B. Laboratory Measuring and Processing}

Chlorophyll-a (chl-a) concentrations of water samples collected in three cruises were measured in a biology lab. Subsamples (1-5 mL) were filtered onto membrane filters [23]. Material on the filters was extracted using a 50:50 mixture of $90 \%$ acetone and dimethylsulfoxide, and the chl-a was quantified before and after acidification using a 10-AU Turner Fluorometer. This allowed final chl-a concentrations to be corrected for the presence of phaeopigments [23]. chl-a concentrations are in unit $\mathrm{mg} / \mathrm{m}^{3}$.

Water samples were filtered through GF/F glass microfiber membrane $(0.70 \mu \mathrm{m})$ under low pressure $(<5 \mathrm{~atm})$. The filters were retained to measure chl-a concentration via HPLC (high performance liquid chromatography). The filtrate was collected and CDOM absorbance $A(\lambda)(200-800 \mathrm{~nm})$ was measured by a Cray-60 spectroradiometer with a 1-cm cuvette and Milli$\mathrm{Q}$ baseline correction. CDOM absorption coefficients $a_{C D O M}$ were then calculated by

$$
a_{C D O M}(\lambda)=\frac{\ln (10) A(\lambda)}{L}
$$




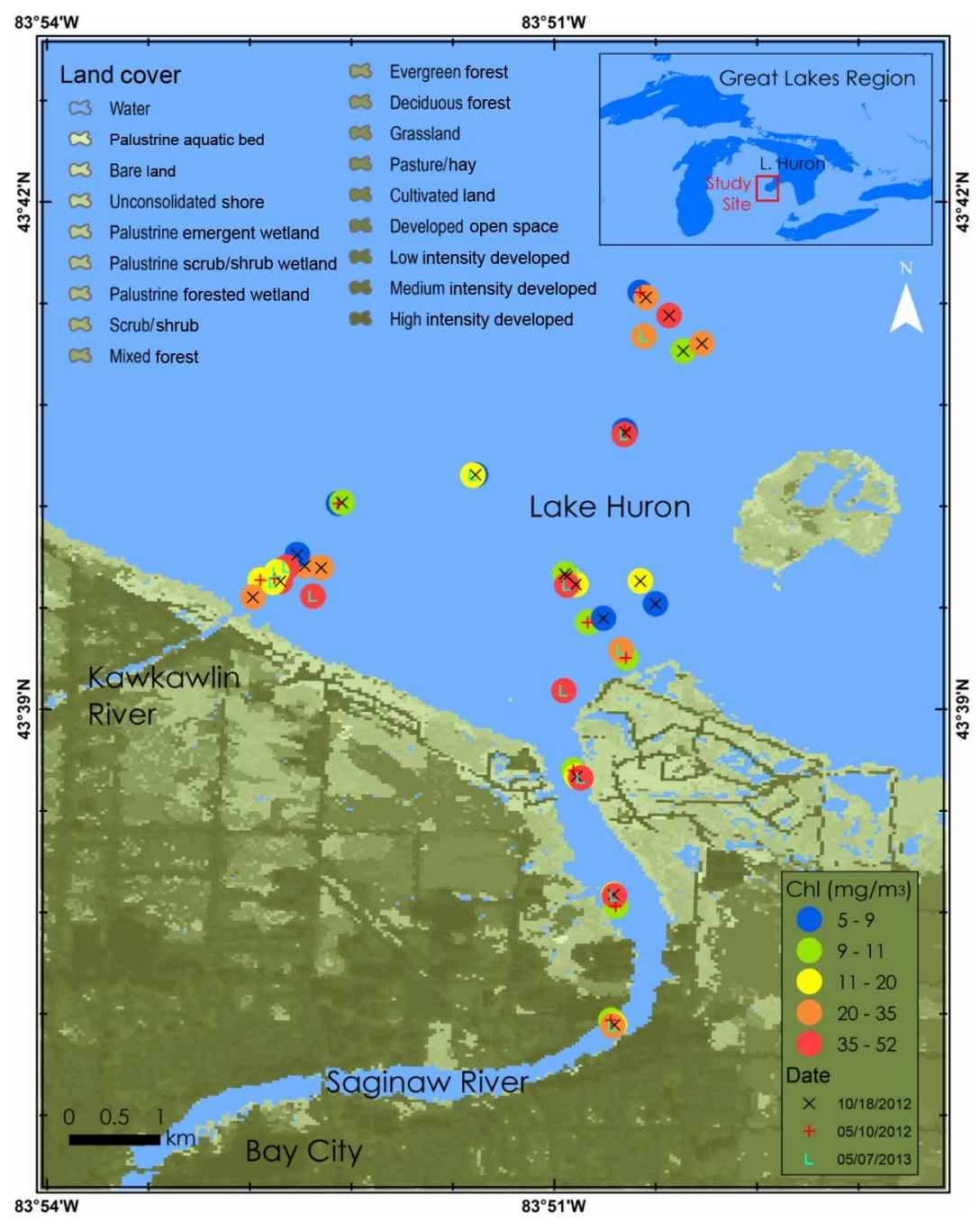

Fig. 1. Study site map for sampling dates and locations, land cover, and chl-a concentrations in the Saginaw River and Kawkawlin River plume regions of Lake Huron.

where $L$ is the path length of the cuvette in meter. In addition, the second filtrate samples were processed to determine DOC concentrations, which were measured using a Shimadzu TOC-V analyzer with high temperature combustion [24].

The remote sensing reflectance $\left(R_{r s}\right)$ was calculated by

$$
R_{r s}=\frac{L_{t}-\rho L_{i}}{E_{s}}
$$

where $\rho$ is the factor representing the proportion of the incident light reflected by the water surface, which was set to a value of 0.028 as suggested by the HyperSAS manual. The $L_{t}, L_{i}$, and $E_{s}$ were derived by calculating the median values of the $\sim 20$ measured in situ spectra at each sampling point.

\section{Simulated Data Set}

The synthetic data used in this study were simulated by Hydrolight [25], a well-known and widely used software environment for radiative transfer simulation. The Hydrolight input model was set to Case 2 water with three ocean color components, and their concentrations were set across extremely wide ranges: chl-a $\left(0-500 \mathrm{mg} / \mathrm{m}^{3}\right), \operatorname{CDOM}\left(0-50 \mathrm{~m}^{-1}\right)$, and NAP (0-500 mg/l) and with logarithmic intervals. For example, we established 33 chl-a representative concentrations $(0,0.1$, $0.2 \ldots 1,2 \ldots 10,20 \ldots 100,200 \ldots 500 \mathrm{mg} / \mathrm{m}^{3}$ ). Therefore, we obtained $33 \times 33 \times 33=35937$ samples. Above-surface spectra were simulated from 400 to $800 \mathrm{~nm}$ with a $5-\mathrm{nm}$ interval. Other simulation parameters were established analogous to those used within the IOCCG (International Ocean Colour Coordinating Group) synthetic data set [26]. Note that the IOCCG synthetic data set is not suitable for algorithm tests in complex inland and coastal waters because its size is relatively small (500 samples), concentration ranges are relatively narrow: chl-a $\left(0.03-30 \mathrm{mg} / \mathrm{m}^{3}\right)$, and $a_{C D O M}$ $\left(0.0025-2.37 \mathrm{~m}^{-1}\right)$, and ocean color components were not completely independent (e.g., CDOM absorptions were set based on chl-a concentrations).

In addition to the full synthetic data set described in the previous paragraph, we created a second synthetic data set (H3000) to be used solely for model validation. This data set contains 3000 samples and their simulation parameters were within the range of the inherent optical properties (IOPs) of the full synthetic data set. However, the IOPs of the H3000 data set (chl-a, CDOM, and NAP) were randomly established. The resulting validation data set is more indicative of the actual optical properties within our 
study area, and were found within a significantly smaller range for all IOPs, chl-a, CDOM, and NAP concentration ranges are $0.297-184.84 \mathrm{mg} / \mathrm{m}^{3}, 0.009-35.36 \mathrm{~m}^{-1}$, and 1.66-289.91 mg/l, respectively.

\section{Accuracy Assessment}

The uncertainty related to the in situ chl-a concentration was evaluated through the comparison of the 20 paired water samples collected at our 10 sampling locations of May 2012. At each location, two samples were taken near simultaneously, separated from each other by a distance $<2 \mathrm{~m}$. In the laboratory, each sample was measured twice and the hence at each location, we have four measured chl-a concentrations. The uncertainty was then evaluated through the following equation:

$$
\text { Uncertainty }=\frac{S_{\max }-S_{\min }}{S_{\text {mean }}} \times 100 \%
$$

where $S_{\text {max }}, S_{\text {min }}$, and $S_{\text {mean }}$ are max, min, and mean values of the four measurements for a given sampling location.

The following statistical variables were used for algorithm assessment and validation:

Mean normalized bias (MNB)

$$
M N B=\frac{1}{N} \sum_{i=1}^{N} \frac{S_{i}^{\text {Estimated }}-S_{i}^{\text {Measured }}}{S_{i}^{\text {Measured }}} .
$$

Mean absolute error (MAE)

$$
M A E=\frac{1}{N} \sum_{i=1}^{N} \frac{\left|S_{i}^{\text {Estimated }}-S_{i}^{\text {Measured }}\right|}{S_{i}^{\text {Measured }}} .
$$

Root mean square error (RMSE)

$$
R M S E=\sqrt{\frac{\sum_{i=1}^{N}\left(S_{i}^{\text {Estimated }}-S_{i}^{\text {Measured }}\right)^{2}}{N-2}} .
$$

Algorithm outputs representing unreasonable or invalid values (i.e., outside of the range from 0 to $1000 \mathrm{mg} / \mathrm{m}^{3}$ ) were not included in our accuracy assessment. As shown in Table I, $N$ represents the total number of algorithm outputs while $n$ is number of valid outputs. Accordingly, the $n / N$ values shown in Table I represent the percentage of algorithm outputs that were deemed valid.

\section{RESUlts AND Discussions}

\section{A. Chl-a Range, Spatial, and Temporal Variations}

The in situ measurements show that water properties in our study site are highly varied in magnitude, time (season), and space. The measured chl-a concentrations ranged from $1.62-51.68 \mathrm{mg} / \mathrm{m}^{3}$ with a mean value $(\mu)$ of $20.46 \mathrm{mg} / \mathrm{m}^{3}$. The range and the mean of our freshwater derived samples are more varied and systematically higher than those of open ocean environments, which are usually lower than $10 \mathrm{mg} / \mathrm{m}^{3}$ [26].

The chl-a range and mean from samples collected during three different sampling campaigns indicate some temporal

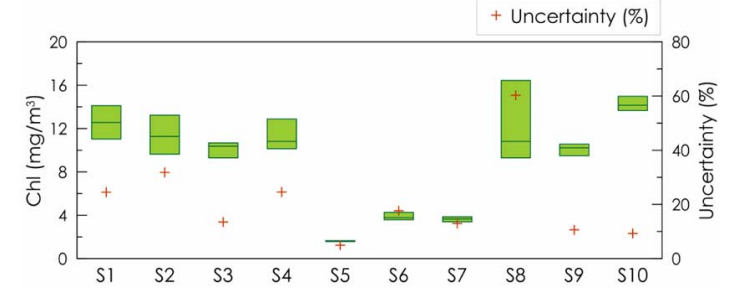

Fig. 2. Measured chl-a concentration ranges and uncertainties for each sampling point collected on May 10, 2012. The floating bars show the max, min, and mean values of each point, and the cross symbols show their uncertainties.

variations due to the mixed effects of precipitation events and seasonal variations. The measured chl-a concentrations from May 10, 2012 displayed a range of $1.62-14.24 \mathrm{mg} / \mathrm{m}^{3}$, with $\mu=8.91 \mathrm{mg} / \mathrm{m}^{3}$ (Fig. 2). The chl-a properties from October 18,2012 increased to $6.52-43.68 \mathrm{mg} / \mathrm{m}^{3}, \mu=18.03 \mathrm{mg} / \mathrm{m}^{3}$. The measurements from May 7, 2013 demonstrated an extreme precipitation effect on chl-a concentrations, since there was the largest precipitation event in 60 years approximately three weeks prior to our sampling campaign. The same season (approximately 1 year later from May 2012) and same sampling sites, chl-a concentrations from May 2013 went up significantly, ranged from $11.57-51.68 \mathrm{mg} / \mathrm{m}^{3}$, with $\mu=$ $32.70 \mathrm{mg} / \mathrm{m}^{3}$.

The samples from each sampling run captured the spatial variation of chl-a concentrations in the two river plume areas, river channel, and bay region. The lowest chl-a concentration $1.62 \mathrm{mg} / \mathrm{m}^{3}$ was observed in the open Saginaw Bay region consistently on each of the sampling dates. The highest chl-a concentrations were observed in the plume area of the Kawkawlin River. Unlike riverine CDOM concentrations, the chl-a concentrations have not demonstrated a clear gradient along the river plumes. This indicates that chl-a concentrations are largely driven by distributions of phytoplankton and algal plants originated in rivers and their diverse network of drainage canals due to eutrophication. The paired samples collected within a $5 \mathrm{~m}$ radius showed that chl-a could display significant differences across short distances [uncertainties calculated by (3)]. The differences ranged from $4.94 \%$ to $60.3 \%$ with a mean value of $21 \%$ (Fig. 2). The complex spatial variations of chla concentrations challenge the consistency of remote sensing estimations of chl-a levels.

Results showed that CDOM and chl-a had no covariation in our samples (Fig. 3). This is consistent to some open sea scenarios reported in [3] and [27]. It should be noted that the lowest, middle, and highest recorded CDOM values all occurred as chl-a were approximately $8-15 \mathrm{mg} / \mathrm{m}^{3}$ (see the vertical shadow area in Fig. 3). Particularly, when chl-a $=8-15 \mathrm{mg} / \mathrm{m}^{3}$ and $\mathrm{CDOM}=1-4 \mathrm{~m}^{-1}$ a complex interaction occurs where one component may highly interfere with the accurate measurement of the second. No correlation between CDOM and chl-a does not indicate that the variation of CDOM levels would not affect remote sensing of chl-a. Our study site displayed highly varied chl-a/CDOM values, sharp sampling gradients, varied responses to precipitation events and seasonal differences, making it an appropriate location at which to evaluate algorithms. 
TABLE I

ASSESSMENT OF CHL-A ALgorithms For In Situ DATA

\begin{tabular}{|c|c|c|c|c|c|c|c|}
\hline No. & Algorithm & Type & $\begin{array}{l}n / N \\
(\%)\end{array}$ & MNB & MAE & $R^{2}$ & RMSE \\
\hline 1 & OC2S & BG Emp & 100 & -0.33 & 0.63 & 0.11 & 18.91 \\
\hline 2 & OC3S & BG Emp & 100 & -0.34 & 0.63 & 0.11 & 18.93 \\
\hline 3 & $\mathrm{OC} 4$ & BG Emp & 100 & -0.37 & 0.62 & 0.17 & 19.18 \\
\hline 4 & OC $3 \mathrm{M}$ & BG Emp & 100 & -0.2 & 0.63 & 0.09 & 17.91 \\
\hline 5 & OC3O & BG Emp & 100 & -0.32 & 0.62 & 0.11 & 18.72 \\
\hline 6 & OC $3 \mathrm{C}$ & BG Emp & 100 & -0.38 & 0.62 & 0.09 & 19.4 \\
\hline 7 & OC2M & BG Emp & 100 & -0.34 & 0.67 & 0.03 & 19.48 \\
\hline 8 & $\mathrm{OC} 2 \mathrm{O}$ & BG Emp & 100 & -0.32 & 0.62 & 0.11 & 18.73 \\
\hline 9 & OC4O & BG Emp & 100 & -0.34 & 0.6 & 0.1 & 18.97 \\
\hline 10 & Morel 02 & BG Emp & 100 & -0.03 & 0.63 & 0.12 & 16.58 \\
\hline 11 & Morel 03 & BG Emp & 100 & 0.49 & 1.08 & 0 & 17.53 \\
\hline 12 & Morel 04 & BG Emp & 100 & 2.46 & 2.48 & 0.12 & 24.64 \\
\hline 13 & CalCOFI 4 & BG Emp & 100 & -0.43 & 0.63 & 0.33 & 19.4 \\
\hline 14 & CalCOFI 3 & BG Emp & 100 & -0.43 & 0.65 & 0.13 & 20 \\
\hline 15 & CalCOFI $2 \mathrm{C}$ & BG Emp & 100 & 0.26 & 0.77 & 0.11 & 14.74 \\
\hline 16 & CalCOFI 2I & BG Emp & 100 & -0.13 & 0.6 & 0.12 & 17.38 \\
\hline 17 & POLDER & BG Emp & 100 & 3.58 & 3.63 & 0.01 & 46.05 \\
\hline 18 & OCTS-p & BG Emp & 100 & 0.2 & 0.9 & 0 & 17.18 \\
\hline 19 & OCTS-c & BG Emp & 100 & -0.02 & 0.66 & 0.11 & 16.45 \\
\hline 20 & C3B & BG Emp & 100 & -0.64 & 0.74 & 0.02 & 22.13 \\
\hline 21 & GPs & BG Emp & 100 & -0.43 & 0.64 & 0.12 & 20.18 \\
\hline 22 & Aiken-C & BG Emp & 100 & -0.64 & 0.73 & 0.13 & 21.9 \\
\hline 23 & Aiken-P & BG Emp & 100 & -0.53 & 0.69 & 0.12 & 20.83 \\
\hline 24 & Carder-S & BG Emp & 100 & -0.54 & 0.72 & 0.24 & 22.93 \\
\hline 25 & QAA-4 & Semi. Emp & 78.05 & -0.09 & 0.75 & 0.16 & 19.54 \\
\hline 26 & QAA-5 & Semi. Emp & 82.93 & 1.73 & 1.89 & 0.28 & 53.62 \\
\hline 27 & GSM & MIM & 100 & -0.12 & 0.55 & 0.02 & 17.46 \\
\hline 28 & Boss & MIM & 97.56 & -0.59 & 0.65 & 0.3 & 17.79 \\
\hline 29 & Lyon & MIM & 97.56 & -0.5 & 0.52 & 0.47 & 16.8 \\
\hline 30 & Brando & MIM & 92.68 & 0.53 & 0.87 & 0.54 & 25.51 \\
\hline 31 & Gitelson 2B & Red-NIR & 95.12 & 1.07 & 1.2 & 0.12 & 19.02 \\
\hline 32 & Gitelson 3B & Red-NIR & 80.49 & -0.18 & 0.55 & 0.45 & 16.01 \\
\hline 33 & Le 4B & Red-NIR & 85.37 & -0.06 & 0.65 & 0.16 & 16.35 \\
\hline 34 & Le 4BC & Red-NIR & 82.93 & -0.11 & 0.57 & 0.54 & 12.91 \\
\hline
\end{tabular}

Note: Algorithm No. 1-24 blue-green (BG) band ratio models: $N$ is the number of data tested, while $n$ is the number of valid retrievals. References: Algorithm No. 1-9: NASA Ocean Color Chlorophyll (OC) v6 (http://oceancolor.gsfc.nasa.gov/ANALYSIS/ocv6/); No. 10-23: [5]; No. 24-29: [26], IOCCG website (http://www.ioccg.org/groups/software.html); No. 30: [32]; No. 31-32: [17]; No. 33-34: [18], [19].

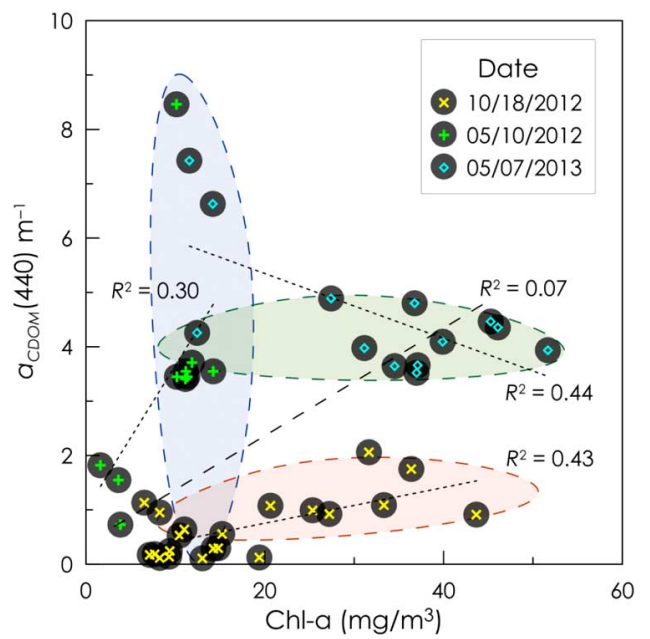

Fig. 3. Correlations between measured $a_{C D O M}(440)$ and chl-a. Their R-squares for data collected on May 2012, October 2012, and May 2013 are $0.30,0.43$, and 0.44 , respectively. For all data, $R^{2}=0.07$. The cycled areas are for individual sampling cruise.

\section{B. Above-Surface Spectra}

The measured above-surface spectra $\left(R_{r s}\right)$ from each sampling location are shown in Fig. 4. The spectral shapes and features are typical to freshwater environments as those observed from other studies [17], [18]. A common feature is the steady increase in $R_{r s}$ from 400 to $570 \mathrm{~nm}$. The steady increase corresponded to a pronounced chl-a absorption feature at $\sim 667 \mathrm{~nm}$. Some of these spectral features correspond to the level of CDOM as described by Zhu et al. [28]. This previous research proved that the quality of spectra from in situ measurements is satisfactory. Another possible factor that may affect on $R_{r s}$ is the NAP [14], but generally water turbidity in the study site is moderate, since the measured spectra do not show significant uplift within long wavelength $>750 \mathrm{~nm}$ due to the backscattering from NAP. Visually, we cannot tell if the remote sensing reflectances (spectra) are related to chl-a concentrations, since they are not clustered with respect to their relative chlorophyll concentration. If this was indeed true, estimating chl-a via simple clustering tools would be possible, and more sophisticated algorithms would not be needed. Therefore, we examined 34 available algorithms for extracting chl-a information from a complex freshwater environment.

\section{Red-NIR Band Ratio Outperform Other Algorithms}

Results showed that four red-NIR 2-B, 3-B, and 4-B band ratio models (No. 31-34, in Table I) outperform the other algorithms (No. 1-30) for in-land waters. The 34 unaltered (original parameterization) algorithms were evaluated with the same data set consisting of all 39 samples collected throughout the sampling campaigns. Algorithms 1-30 can be thought 


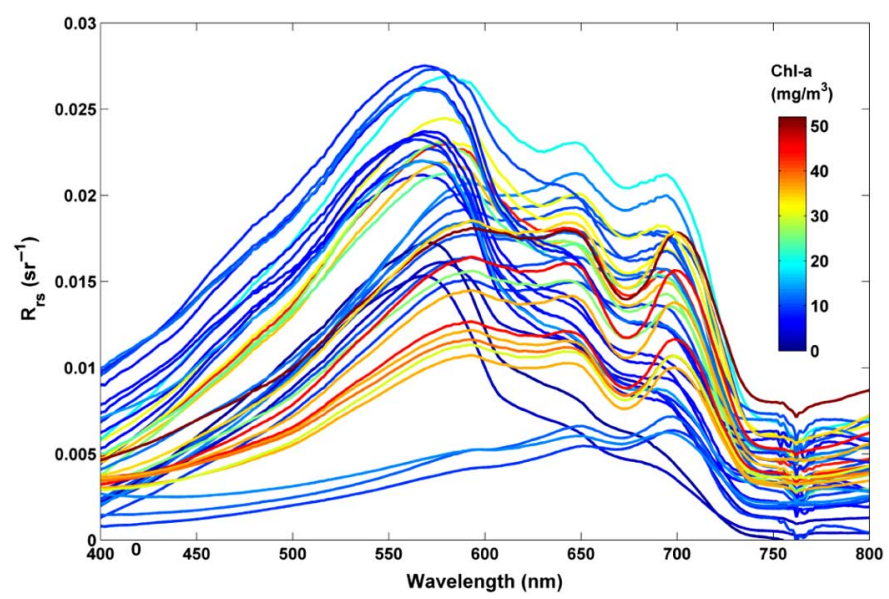

Fig. 4. Measured remote sensing reflectance, colored by chl-a concentrations.

of as alternatives to the red-NIR methods, including blue-green band ratio, semianalytical and MIM (matrix inversion method) models. Some of the alternative algorithms use $a_{p h}(440)$ (chl-a absorption coefficients at $440 \mathrm{~nm}$ ) as a proxy for chl-a concentration. In this case, we converted $a_{p h}(440)$ into a concentration (C) $\left(\mathrm{mg} / \mathrm{m}^{3}\right)$ using the following equation [5]:

$$
a_{p h}(440)=0.0403 \times(C)^{0.668} .
$$

These results demonstrated that red-NIR multiband algorithms are capable of performing well in complex inland freshwaters as represented by our study site. The evaluation results averaged among all red-NIR algorithms was a mean MAE = $0.74, R^{2}=0.32$, and RMSE $=16.07$. The chl-a estimations from the Gitelson 3-B is as accurate as that from two 4-B models (Le 4BC, and Le 4B, Fig. 5). However, none of the tested 3-B and 4-B algorithms displayed significant improvements over that of the 2-B algorithm.

Our results also indicated that at red-NIR band ratio models performed better than the blue-green band ratio models (algorithms No. 1-23), which all underestimated the chl-a measurements (median $\mathrm{MNB}=-0.33$, mean $\mathrm{MAE}=0.89$, $R^{2}=0.10$, and RMSE $=20.23$ ).

This study revealed the advantages of red-NIR algorithms (No. 31-34) over semianalytical (no. 28-30), and MIM models. Despite the fact that many semi-analytical and MIM algorithms were specifically designed for use in marine estuarine and coastal/inland case 2 waters, they were unsatisfactory in estimating chl-a concentrations in waters from our study site (mean MAE $=0.85, R^{2}=0.29$, and RMSE $=24.81$ ).

\section{Spectral Interference From CDOM}

Our result also indicated that CDOM levels could interfere with the estimation of chl-a concentrations from remote sensing measurements. This was made evident when the measured versus predicted chl-a concentrations were plotted against each other (Fig. 5). Two distinct clusters are evident, as outlined by the vertical and horizontal dashed regions. Note that these results are clustered in two chl-a concentration ranges in Fig. 5(a)-(f), and Fig. 5(h)-(i). All algorithms overestimated

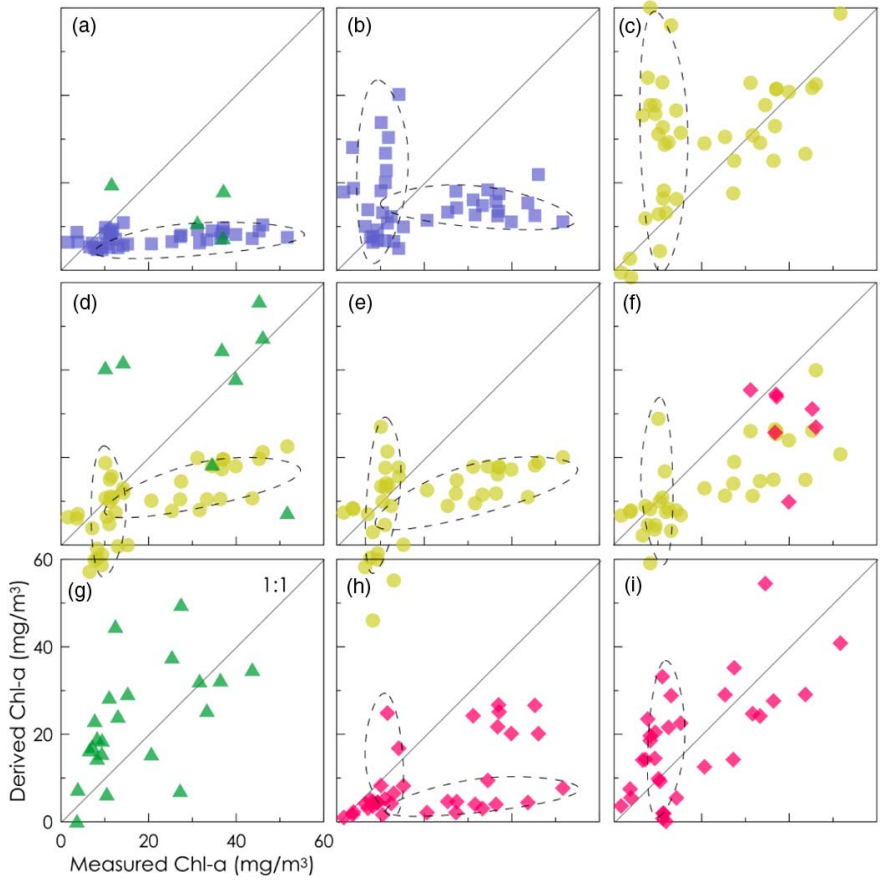

Fig. 5. Measured versus derived chl-a concentrations from nine algorithms. (a) OC4. (b) Morel 3. (c) Gitelson 2B. (d) Gitelson 3B. (e) Le 4B. (f) Le 4BC. (g) QAA V5. (h) Boss. (i) Brando.

the low chl-a concentrations $\left(\leq 10 \mathrm{mg} / \mathrm{m}^{3}\right)$, such as the Morel 03 model [Fig. 5(b)]. The largest estimation errors occurred around a chl-a concentration of $10 \mathrm{mg} / \mathrm{m}^{3}$. In most instances, these two clusters are separated by the chl-a concentration of $10 \mathrm{mg} / \mathrm{m}^{3}$. The pattern of predicted versus measured chla are similar to that of chl-a versus CDOM levels displayed in Fig. 3. The similar distribution patterns suggest that the two clusters of over- and under-estimation might indeed be caused by the spectra interference of CDOM, where considerable CDOM absorptions were mistaken as chl-a absorptions. Our data illustrates that interference from CDOM absorptions (ranging from 1-4 $\mathrm{m}^{-1}$ ) was prevalent in those cases where chl-a $>10 \mathrm{mg} / \mathrm{m}^{3}$. Therefore, CDOM is a significant interference factor for chl-a estimation in estuarine and lakeshore CDOM-rich waters. Unfortunately, understanding the interferences of optical properties between biological and/or organic substances remains a challenge for aquatic color research.

\section{E. Sensitivity of 2-B Red-NIR Band Ratio Models}

It is a general concept that 4-B model is better than 3-B and then better than 2-B [17], [18], [21]. However, so far there are no complete comparisons among the three models. Interestingly, Gurlin et al. [29] recently reported that 2-B model using two MERIS bands was even better than 3-B models. In order to gain a better understanding of how sensitive 2-B red-NIR models are to the manipulation of band position (wavelength domain), we further applied our in situ and synthetic data sets to 2-B red-NIR models configured with varied bandsets and compared it with 3-B and 4-B models. Through these 
TABLE II

BAnds ANd Parameters Used IN 2/3/4B CHL-A Models

\begin{tabular}{|c|c|c|c|c|c|c|c|c|c|c|}
\hline \multirow{2}{*}{$\begin{array}{l}\text { Model } \\
\#\end{array}$} & \multirow{2}{*}{$\begin{array}{l}\text { Model } \\
\text { name }\end{array}$} & \multicolumn{4}{|c|}{ Band used (nm) } & \multirow[t]{2}{*}{$k$} & \multirow[t]{2}{*}{$b$} & \multirow[t]{2}{*}{$R^{2}$} & \multirow[t]{2}{*}{ RMSE } & \multirow{2}{*}{$\begin{array}{l}\text { Data set / } \\
\text { reference }\end{array}$} \\
\hline & & $B_{1}$ & $B_{2}$ & $B_{3}$ & $B_{4}$ & & & & & \\
\hline \multicolumn{11}{|c|}{ This study } \\
\hline 1 & $2 \mathrm{SG}$ & 665 & 685 & 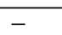 & - & 154.19 & -128.09 & 0.7 & 6 & In situ \\
\hline 2 & $2 \mathrm{MR}$ & 665 & 705 & - & _- & 37.74 & -15.59 & 0.17 & 9.91 & In situ \\
\hline 3 & $2 \mathrm{MO}$ & 667 & 748 & - & - & 6.98 & 12.82 & 0.004 & 10.89 & In situ \\
\hline 4 & $2 \mathrm{SG}$ & 665 & 760 & - & - & 119.62 & -26.2 & 0.77 & 56.59 & Synthetic \\
\hline 5 & $2 \mathrm{MR}$ & 665 & 705 & - & - & 167.99 & -117.07 & 0.616 & 73.02 & Synthetic \\
\hline 6 & $2 \mathrm{MO}$ & 665 & 745 & - & - & 113.17 & -25.11 & 0.766 & 56.97 & Synthetic \\
\hline 7 & $3 \mathrm{SG}$ & 666 & 686 & 730 & - & 391.37 & 22.63 & 0.74 & 5.56 & In situ \\
\hline 8 & $3 \mathrm{MR}$ & 665 & 705 & 755 & _- & 150.31 & 18.54 & 0.088 & 10.42 & In situ \\
\hline 9 & $3 \mathrm{SG}$ & 655 & 680 & 740 & - & 464.22 & -18.65 & 0.78 & 55.56 & Synthetic \\
\hline 10 & $3 \mathrm{MR}$ & 665 & 705 & 755 & - & 154.61 & 40.15 & 0.7 & 64.4 & Synthetic \\
\hline 11 & $4 \mathrm{SG}$ & 665 & 685 & 700 & 720 & -141.77 & 26.51 & 0.59 & 6.75 & In situ \\
\hline 12 & $4 \mathrm{SG}$ & 670 & 605 & 725 & 760 & -25.66 & 10.91 & 0.757 & 58.06 & Synthetic \\
\hline 13 & $4 \mathrm{MR}$ & 665 & 620 & 750 & 760 & -8.02 & -3.52 & 0.759 & 57.85 & Synthetic \\
\hline \multicolumn{11}{|c|}{ Previous studies } \\
\hline 14 & $2 \mathrm{SG}$ & 670 & 720 & - & - & 59.826 & -17.546 & 0.788 & 8.39 & Gitelson (2007) \\
\hline 15 & 2 SG & 666 & 713 & - & - & N/A & N/A & N/A & N/A & [29] \\
\hline 16 & $2 \mathrm{MR}$ & 665 & 705 & - & - & N/A & N/A & 0.95 & N/A & [29] \\
\hline 17 & $2 \mathrm{MO}$ & 667 & 748 & - & - & 136.3 & -16.2 & 0.928 & N/A & [17] \\
\hline 18 & $2 \mathrm{MO}$ & 667 & 748 & - & - & 190.34 & -32.45 & 0.75 & N/A & [29] \\
\hline 19 & $3 \mathrm{SG}$ & 671 & 710 & 740 & - & 125 & 16 & 0.94 & 14.6 & {$[20]$} \\
\hline 20 & $3 \mathrm{SG}$ & 675 & 695 & 730 & - & 178.94 & 10.139 & 0.811 & 7.9 & Gitelson (2007) \\
\hline 21 & $3 \mathrm{SG}$ & 666 & 712 & 724 & - & N/A & N/A & N/A & N/A & [29] \\
\hline 22 & $3 \mathrm{SG}$ & 660 & 692 & 740 & - & 434.78 & 14.78 & 0.87 & N/A & [18] \\
\hline 23 & $3 \mathrm{SG}$ & 630 & 710 & 740 & - & N/A & N/A & 0.97 & N/A & [19] \\
\hline 24 & $3 \mathrm{MR}$ & 665 & 715 & 750 & - & 117.42 & 23.09 & 0.94 & N/A & [17] \\
\hline 25 & $3 \mathrm{MR}$ & 665 & 705 & 755 & - & N/A & N/A & 0.95 & N/A & [29] \\
\hline 26 & $4 \mathrm{SG}$ & 663 & 693 & 705 & 740 & 103.09 & 13.07 & 0.97 & N/A & [18] \\
\hline 27 & $4 \mathrm{SG}$ & 650 & 710 & 700 & 730 & 61.757 & 25.221 & 0.97 & N/A & {$[19]$} \\
\hline \multicolumn{11}{|c|}{ Median band values for each multiband model, calculated from all above results } \\
\hline & $2 \mathrm{~B}$ & 665 & 720 & & & & & & & \\
\hline & $3 \mathrm{~B}$ & 665 & 705 & 740 & & & & & & \\
\hline & $4 \mathrm{~B}$ & 665 & 685 & 705 & 740 & & & & & \\
\hline
\end{tabular}

Note: In column 2, the number in model name indicates how many bands used, and SG, MR, and MO indicate the bands derived from the calibrated suggestions, MERIS, and MODIS available bands, respectively. $k$ and $b$ are slope and intersect in the model of $(C)=k X+b$.

calibration efforts, we aimed to better understand the advantages and limits of each of red-NIR band ratio models for chl-a estimation.

1) 2-B models: Generic two-band ratio models for estimating chl-a concentrations are in the form of the equation below

$$
[C] \propto X=\frac{B_{1}}{B_{2}} .
$$

There are two main considerations when evaluating red-NIR band ratio algorithms. The first is to select the optimal combinations of the two wavelengths, B1 and B2, from the wavelength range of $400-800 \mathrm{~nm}$. The second is to set the model parameterization so that there is a good correlation between $X$ (band ratio index) and the chl-a concentration $C$ (Table II). The selection of the optimal wavelengths and parameterization are based on RMSE between the estimated and our measured in situ chl-a concentrations.

The RMSE generated from each of the possible two-band combinations ranged from 7.2 to 10.8 with a mean value 10.56 [Fig. 6(a)]. The lowest RMSE corresponded to a pair of bands separated by only $5 \mathrm{~nm}[\mathrm{~B} 1=541 \mathrm{~nm}$ and $\mathrm{B} 2=537 \mathrm{~nm}$, see R1 region in Fig. 6(a)]. The close proximity of the two bands (near the diagonal region) very likely indicates that these two wavelengths contain redundant spectral information or would not truly be two independent variables. It is also impractical since most satellite sensors do not provide high enough spectral resolution in $5 \mathrm{~nm}$. For example, MERIS, MODIS, and Hyperion, popular ocean satellite sensors, have bands separated by $10 \mathrm{~nm}$. Therefore, we implemented (9) as a constraint

$$
|B 1-B 2| \geq 10 \mathrm{~nm} \text {. }
$$

Under such constraint, those relatively low RMSE regions close to the diagonal line [dashed lines in Fig. 6(a) and (b)] violate (9); so these bands were removed from consideration. Therefore, our results showed that wavelengths at 685 and $665 \mathrm{~nm}$ [R2 region in Fig. 6(a)] correspond to the best 2-B model [Model 1 in Table II, $R^{2}=0.7$ and RMSE $=6.0$, Fig. 7(a)]. A model configured as such should be thought as a dual-red band ratio model instead of the red-NIR model.

The resulted RMSE ranged from 55.16 to 117.76 with a mean value of 107.69 [Fig. 6(b)], when the same processes were applied to the synthetic data set that has a much wider range of chl-a concentrations $\left(0.1-1000 \mathrm{mg} / \mathrm{m}^{3}\right)$. The area of the two band combination associated to the lowest RMSE values crossed both the red and NIR wavelengths [R5 in Fig. 6(b)]. The optimal two bands were 665 and $760 \mathrm{~nm}$ (Model 4 in Table II), with $R^{2}=0.78$ and RMSE $=55.56$ [Fig. 7(i)].

Our results also indicate that blue-green band ratio models, which are often used for open sea waters are not suitable for complex inland waters. There were no paired blue and green bands selected as significant in our analysis, although either 

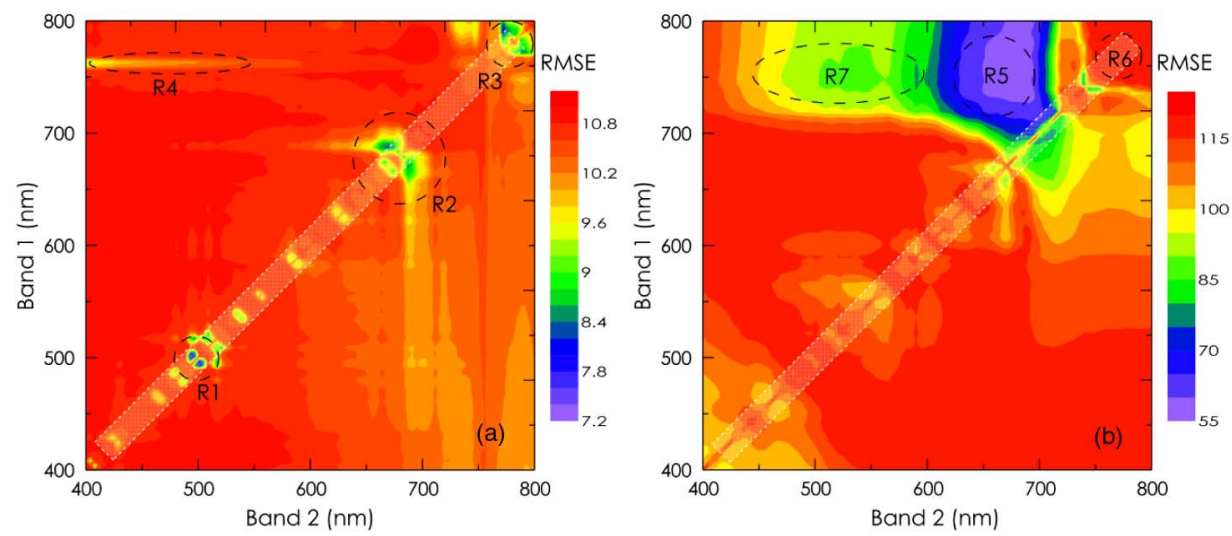

Fig. 6. Determining the best two bands in 2-B models using (a) in situ data and (b) synthetic data. The in situ and synthetic results are in 1 and $5 \mathrm{~nm}$ resolutions, respectively. The suggested best two bands are B1 $=685 \mathrm{~nm}$ and B2 $=665 \mathrm{~nm}$ for in situ data, and B1 $=760 \mathrm{~nm}$ and B2 = $665 \mathrm{~nm}$ for synthetic data.
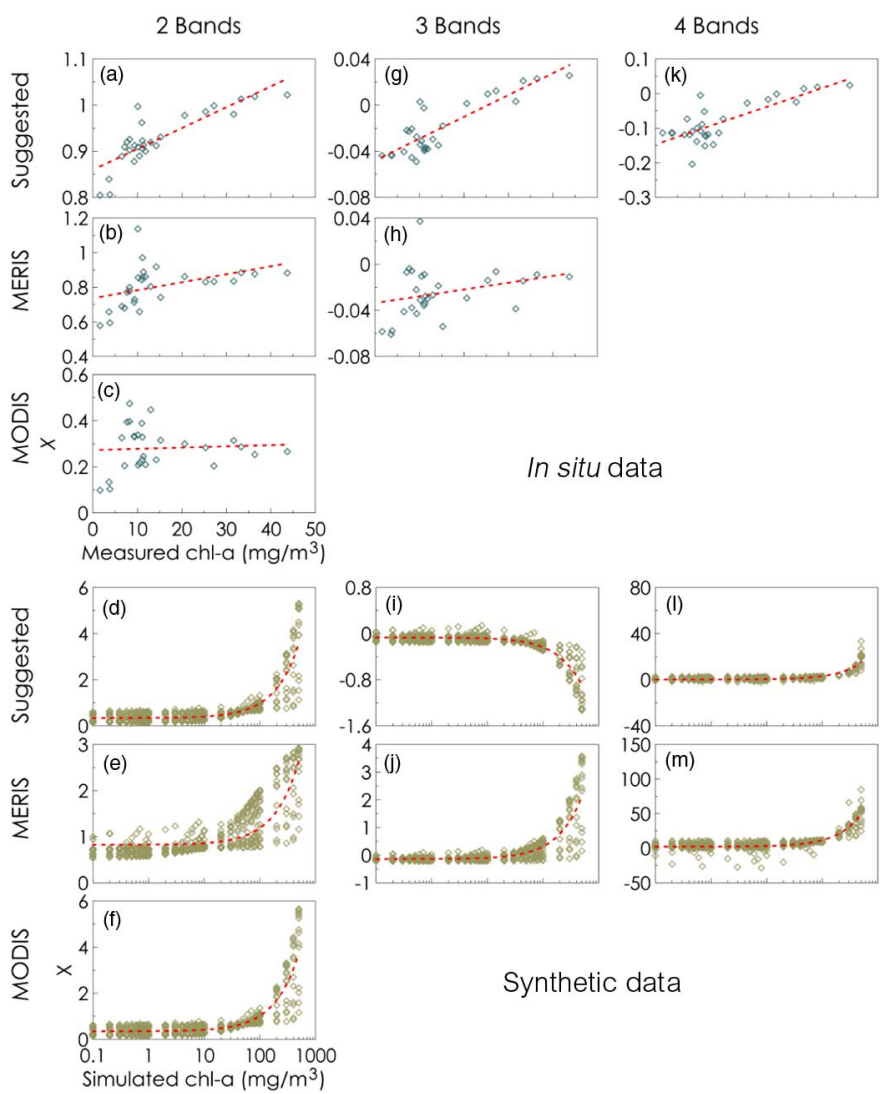

Synthetic data

Fig. 7. Calibrations for multiband models for both the in situ and synthetic data sets. Values of Y-axis are the remote sensed indices derived from 2-B, 3-B, and 4-B models. The values of $\mathrm{X}$ are the measured chl-a concentrations (mg/m ${ }^{3}$ ). (a) $\mathrm{R}^{2}=0.70$. (b) $\mathrm{R}^{2}=0.17$. (c) $\mathrm{R}^{2}=0.0008$. (d) $\mathrm{R}^{2}=0.77$. (e) $\mathrm{R}^{2}=0.61$. (f) $\mathrm{R}^{2}=0.77$. (g) $\mathrm{R}^{2}=0.74$. (h) $\mathrm{R}^{2}=0.09$. (i) $\mathrm{R}^{2}=0.78$. (j) $\mathrm{R}^{2}=0.70$. (k) $\mathrm{R}^{2}=0.59$. (l) $\mathrm{R}^{2}=0.76$. (m) $\mathrm{R}^{2}=0.76$.

blue or green wavelength paired with a NIR in B1 [region 4 in Fig. 6(a) and region 7 in Fig. 6(b)] had satisfactory chl-a estimation. It is worth noting that the regions (hotspots) leading to low RMSE for the synthetic data [R5 in Fig. 6(b)] did not overlap with those for our in situ results [R2 in Fig. 6(a)]. This illustrates how critical proper calibration of current 2-B models is when applied to inland waters with high CDOM levels.
Spectral interferences among chl-a, CDOM, and sediment in freshwaters, proper parameterization and the selection of optimal wavelengths for chl-a estimation all vary greatly depending on conditions at specific sites.

Band selection for satellite sensors is not as flexible as that for high-resolution in situ spectroradiometer data. The best wavelengths for a 2-B model are band $7(665 \pm 10 \mathrm{~nm})$ and band $9(708.75 \pm 10) \mathrm{nm}$ for MERIS [RMSE $=9.91$, Fig. 7(b)] when the calibration was conducted with in situ data. Similarly, the best wavelengths for a 2-B model for MODIS are band $13(662-672 \mathrm{~nm})$ and band $15(743-753) \mathrm{nm}$ with $(\mathrm{RMSE}=10.89)$ in Fig. 7(c). The actual 2-B models calibrated with in situ data for MERIS and MODIS bands are models 2 and 3 in Table II, respectively. These results show no significant difference between MODIS and MERIS sensors for relatively low chl-a concentrations $\left(0-50 \mathrm{mg} / \mathrm{m}^{3}\right)$ measured for specific study sites (in situ data). In contrast, MODIS data performed slightly better (RMSE: 56.97) than MERIS bands (RMSE = 73.02) as specified by models 5-6 of Table II. RMSE values derived from satellite sensors are in the similar ranges to those derived from suggested bands for both in situ and synthetic data calibrations. Therefore, our results confirmed that using satellite bands are as efficient as using in situ spectroradiometers for aquatic chl-a estimation.

2) 3-B Models: The generic 3-B models are usually in the form of the following equation:

$$
(C) \propto X=\left(\frac{1}{B_{1}}-\frac{1}{B_{2}}\right) B_{3} .
$$

Determination of the optimal wavelengths at $1 \mathrm{~nm}$ spectral resolution for the 3-B models involved the examination of approximately 64 million three-band combinations from 400 to $800 \mathrm{~nm}$. In order to increase computational efficiency, we resampled our in situ data to $5 \mathrm{~nm}$ resolution. Fig. 8(a) shows the best band combinations as indicated by the lowest RMSE without the constraint of (9). With the constraint of (9) in place, the lowest three-band RMSE of 5.56 [Fig. 8(c)] was achieved (Model 7, Table II; B1 $=666 \mathrm{~nm}, \mathrm{~B} 2=686 \mathrm{~nm}$, and $\mathrm{B} 3=730 \mathrm{~nm}$ ). The first two bands, B1 and B2 are very close to those selected for the dual-red band ratio model shown above. The B3 is close to the $\mathrm{B} 2$ in 2-B model calibrated from using 

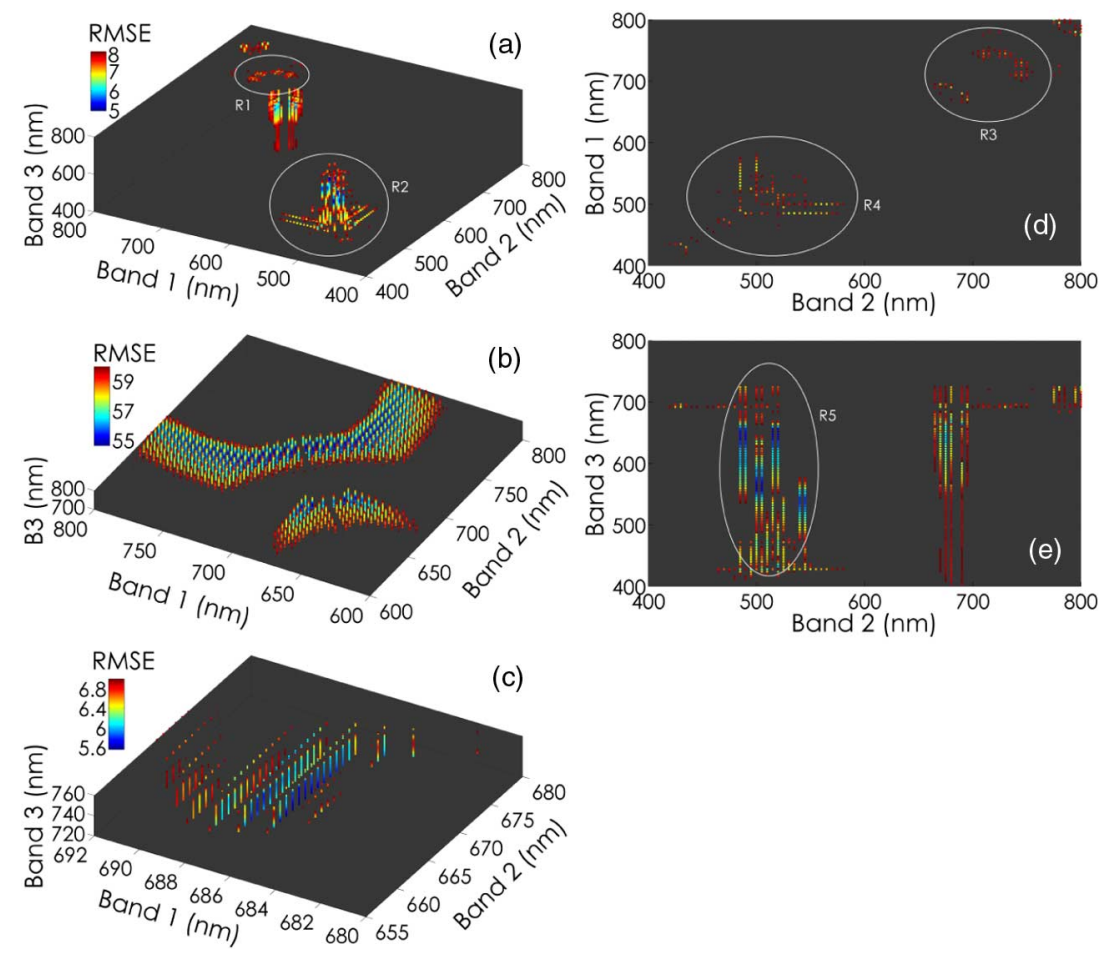

Fig. 8. Determining the best three bands in 3-B models using (a) in situ data, where RMSE $>8$ are not shown and (b) synthetic data, where RMSE $>60$ are not shown. (c) illustrates the zoom-in region where the suggested three bands were selected for B1 from 650 to $680 \mathrm{~nm}$, B2 from 680 to $710 \mathrm{~nm}$, and B3 from 730 to $760 \mathrm{~nm}$, at $1 \mathrm{~nm}$ intervals. (d) is the top view of the subfigure (a), and (e) is the side view of the subfigure (a).

synthetic data sets. With additional band, the calibrated 3-B band model (RSMB, 5.56) has no significant improvement over both dual-red 2-B (RSME 6.0) models.

When the synthetic data set was used to calibrate 3-B models, the lowest RMSE of 54.61 was achieved with the three-band combination: $\mathrm{B} 1=705 \mathrm{~nm}, \mathrm{~B} 2=720 \mathrm{~nm}$, and B3 $=740 \mathrm{~nm}$. All three bands are in the NIR [eagle-shaped zone; Fig. 8(b)]. The best band combination utilizing a red band was 655 , 680, and $740 \mathrm{~nm}$ (Model 9 in Table II). Including this single red band represented only a slight improvement in RMSE from 54.61 to 55.56 . Therefore, utilizing the synthetic data set for calibration had very little influence on three-band model results. Comparing to 2-B model and synthetic scenario, B2 = $680 \mathrm{~nm}$ is the additional band. The best three band combinations derived with in situ data (Model 7 in Table II) are essentially equivalent to that derived from the synthetic data set (Model 9 in Table II).

3-B models can be applied to the MERIS bands by using $\mathrm{B} 1=665 \mathrm{~nm}, \mathrm{~B} 2=705 \mathrm{~nm}$, and $\mathrm{B} 3=755 \mathrm{~nm}$. The three bands derived from both in situ (Model 8 in Table II) and synthetic data (Model 10 in Table II) are the same. Corresponding RMSE values are 10.42 and 64.4 for in situ and synthetic data, respectively. The suggested 3-B models are consistent to that introduced by Gurlin et al. [29]. Unfortunately, MODIS does not have bands near enough to all of the three optimal bands to make a 3-B red/NIR MODIS models possible. Ultimately, chl-a estimation via 3-B models had only a limited influence of model performance compared to 2-B models, approximately $5 \%$ with respect to in situ data and $11 \%$ with respect to synthetic data.
Comparing the results from our analysis and other previous studies (Table II) demonstrated that the two optimal bands in the 3-B models are associated with the spectral properties of chl-a. B1 is associated with an absorption peak of chl-a at $665 \mathrm{~nm}$. B2 is associated with the two local maximums of chl-a florescence at 673 and $726 \mathrm{~nm}$. It is common to set B2 at approximately $700 \mathrm{~nm}$ in many existing models. But our results suggest that B2 should be shifted to a slightly lower wavelength region centered at $685 \mathrm{~nm}$. The third band, B3 remained relatively fixed to the range: $730-740 \mathrm{~nm}$ for the majority of 3-B models. An exception is Gurlin's proposed model utilized a slightly smaller wavelength centered at $724 \mathrm{~nm}$ [29].

3) 4-B Models: Equation below is the general form of four bands (4-B) chl-a models

$$
[C] \propto X=\left(\frac{1}{B_{1}}-\frac{1}{B_{2}}\right)\left(\frac{1}{B_{4}}-\frac{1}{B_{3}}\right)^{-1} .
$$

The number of four-band combinations across $400-800 \mathrm{~nm}$ is much greater than that for 3-B models. A dual-band tuning technique similar to those single-band tuning methods in the literature [10], [30] was used to identify an optimal four-band combination leading to the lowest RMSE. Via band-tuning, the optimal band selection process was divided into three steps. First was to preselect the best two bands: $\mathrm{B} 1=666 \mathrm{~nm}$ and $\mathrm{B} 2=686 \mathrm{~nm}$ which were the suggested two bands in the best 3-B model (Model 7). Then the optimal B3 and B4 were determined by checking all possible two-band combinations against the fixed B1 and B2. The resultant best B 3 and B4 were 700 and $720 \mathrm{~nm}$, respectively [Fig. 9(a)]. The final step is to re-examine the best $\mathrm{B} 1$ and $\mathrm{B} 2$, with the fixed B3, and B4. The re-selected 

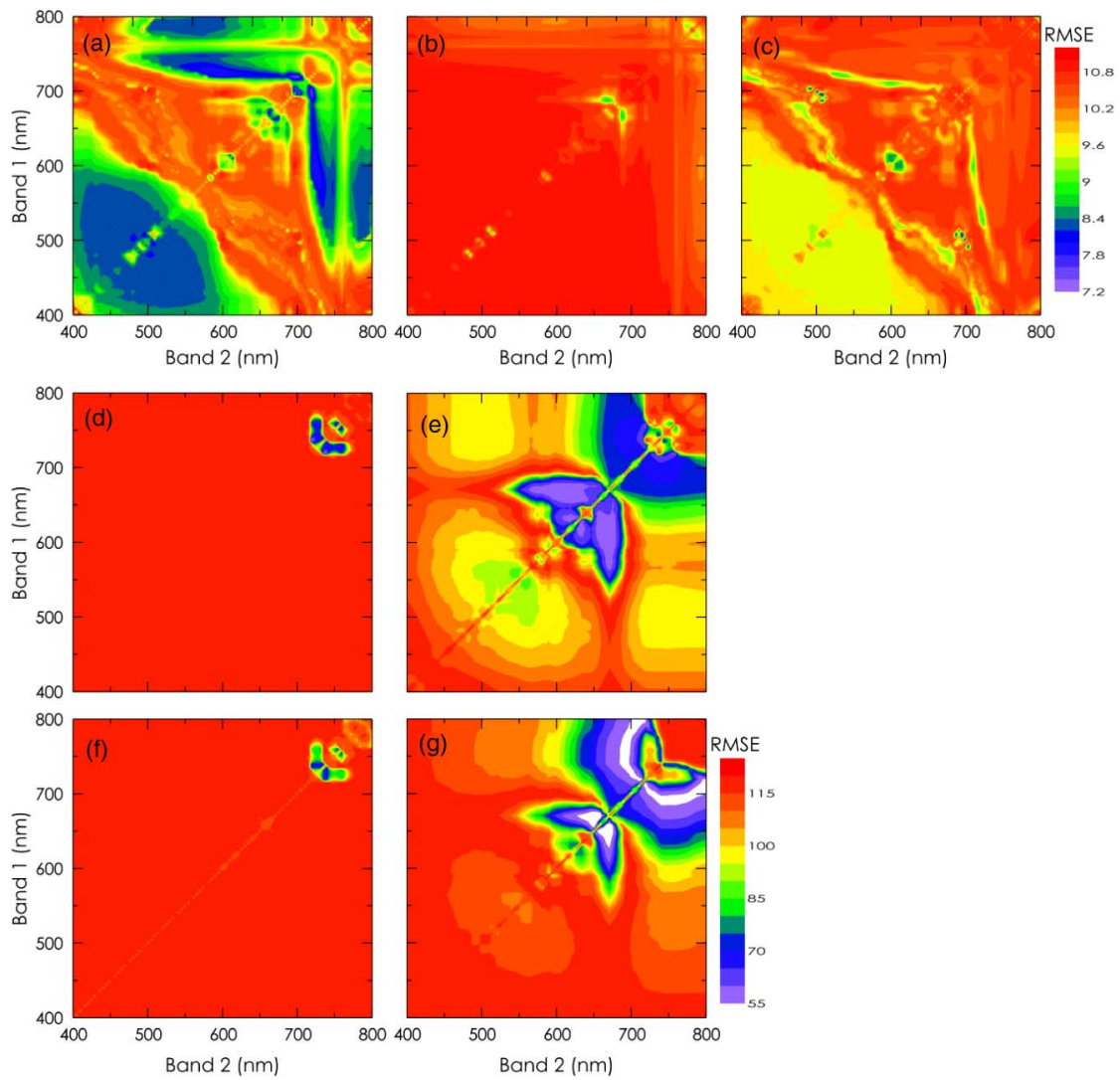

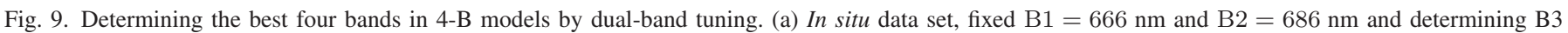

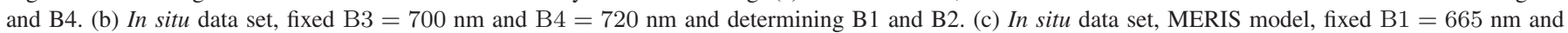

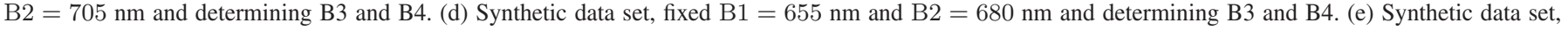

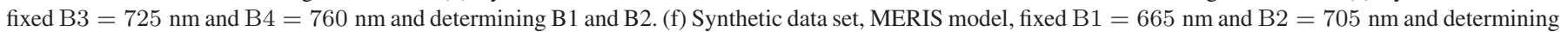
B3 and B4. (g) Synthetic data set, MERIS model, fixed B3 = $750 \mathrm{~nm}$ and B4 = $760 \mathrm{~nm}$ and determining B1 and B2.

optimal B1 and B2 are 665 and $685 \mathrm{~nm}$, respectively [Fig. 9(b)]. The resulted four-band combination is $\mathrm{B} 1=665, \mathrm{~B} 2=685$, $\mathrm{B} 3=700$, and $\mathrm{B} 4=720 \mathrm{~nm}$ (Model 11 in Table II). The B1 and B2 are very consistent to that selected in 2-B model (666 and $686 \mathrm{~nm}$ ).

Optimal four-band combinations derived using the synthetic data set were $\mathrm{B} 1=670, \mathrm{~B} 2=605, \mathrm{~B} 3=725$, and $\mathrm{B} 4=760$ (Model 12 in Table II). The diagrammatic description of the optimal band combination regions are shown in Fig. 9(d) and (e). Two bands (B2 and B4) are very different from those derived from in situ data. This difference indicates that optimal band combinations are indeed dependent on water properties and the range of chl-a concentrations. Conceptually, one might believe that three out of the four bands in a 4-B model should overlap with the wavelengths used in 3-B model, or two bands of a 2-B model. In reality, these wavelengths are not completely independent from each other. Such correlations might have contributed to the wavelength differences between 4-B models derived from in situ and synthetic data sets. A second consideration that may drive the selection of different optimal band combinations is the form of associated mathematical equations. Optimal band combinations are selected differently than the stepwise statistical analysis that ranks significant variables. Due to this mathematical difference, optimal bands in 4-B models should be independent from that selected in the 3-B models.
Performance of estimating chl-a concentrations via 4-B models had no significant improvements over that using 2-B models with respect to our in situ data. The 4-B model derived from in situ data achieved an RMSE of 6.75. In fact, the 2-B models were slightly better (RMSE: 6.0 ) than the 4-B models. This was also true for the synthetic data set, the 2-B model resulted in slight better performance (RMSE: 56.59) over the 4-B model (RMSE: 58.06).

A 4-B model derived from synthetic data for MERIS bands (RMSE: 57.85) achieved about 27\% improvement in terms of RMSE values of estimating chl-a concentrations compared to 2-B models (RMSE: 73.02), although this improvement is still within error margins [Fig. 9(f) and (g)]. This result was obtained by using four band combinations: $\mathrm{B} 1=665 \pm 10 \mathrm{~nm}$ (band 7), B2 = 708.75 \pm 10 (band 9), B3 $=510 \pm 10 \mathrm{~nm}$ (band 4), and $\mathrm{B} 4=760.625 \pm 3.75 \mathrm{~nm}$ [band 11, Fig. 9(c)]. The combination consists of one green, one red and two NIR bands (Model 13 in Table II). The results confirmed that it is indeed feasible to use MERIS bands (RMSE: 58.06) as a substitution for in situ remote sensing techniques (RMSE: 57.85) in estimating chl-a concentration via 4-B models.

4) Evaluation Highlights: There are three major differences between using in situ and synthetic data in evaluating band ratio models for estimating freshwater chl-a concentrations. First, RMSE values from the evaluated algorithms are 


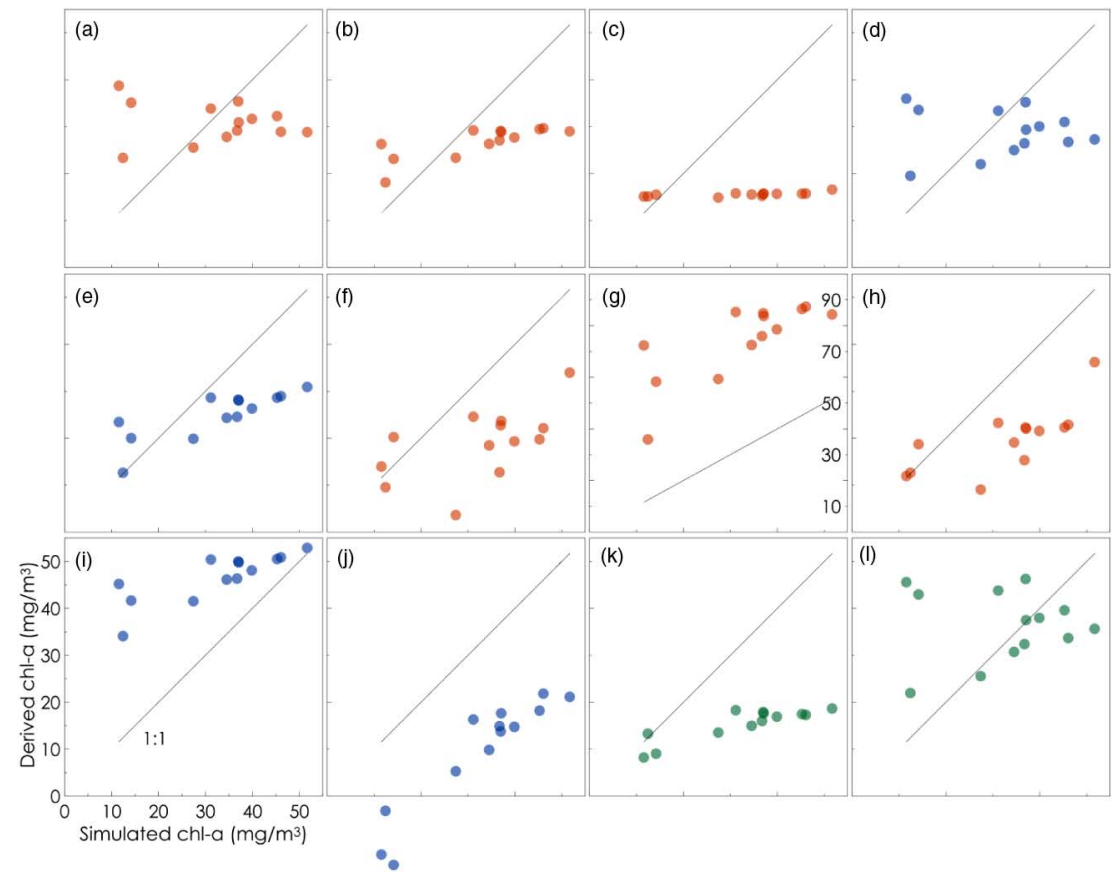

Fig. 10. Validations for multiband chl-a models using in situ (May 2013) data. (a) 2B in situ suggested. (b) 2B in situ MERIS. (c) 2B in situ MODIS. (d) 3B in situ suggested. (e) 3B in situ MERIS. (f) 2B synthetic suggested. (g) 2B synthetic MERIS. (h) 2B synthetic MODIS. (i) 3B synthetic MERIS. (j) 3B synthetic suggested. (k) 4B synthetic suggested. (1) 4B in situ suggested.

heavily influenced by the ranges of chl-a concentrations. Since the range of chl-a concentrations presented in synthetic data are 20 times broader than that of in situ measurements, the resulting RMSE values from this synthetic data are more than 10 times larger than that from using in situ data set. Second, the band ratio indices from in situ data have a limited range from -0.3 to 1.1 which is approximately 150 times smaller than the indices derived from synthetic data (ranged from -50 to 150 ). Therefore, ranges of chl-a concentrations determine the ranges of band ratio indices. Third, the correlations between band ratio indices and chl-a concentrations represented in synthetic data and in situ data are similar, except that $R^{2}$ derived from synthetic data had a narrower range $(0.61-0.78)$ than that from in situ data set (0.0008-0.74). Finally, the optimal band combination for band ratio models varies tremendously with water properties and the range of chl-a concentrations.

Our analysis demonstrated that 2-B band ratio algorithm can perform as well as 3-B and 4-B algorithms. Accordingly, a 2-B band ratio algorithm would be the best choice for chl-a estimation in freshwater environments. Since it requires fewer bands, it should be more robust and less likely to be overfitted/influenced with local measurements and environmental conditions. The two bands calibrated from the in situ and synthetic are both associated with wavelengths sensitive to either peak absorption or maximum fluorescence of chl-a, or a wavelength positioned near the intersect between the absorption curves of chl-a and chl-b.

Red and NIR wavelengths near $700 \mathrm{~nm}$ are selected in all of tested band ratio algorithms. This is consistent to many previous research results in which lower wavelength NIR bands were found to be optimal when applied to the turbid waters of the Lake Taihu, Lake Chaohu, and Three Gorges Reservoir in
China [18], [31]. However, our results indicate that these lower wavelengths may not be suitable to CDOM-rich waters, such as waters at Kawkawlin River plume area (Fig. 1).

5) Validating the Analysis Results With Independent Data Set: We validated all red-NIR band ratio models (shown in Table II) with two independent data sets: one is the in situ data collected on May 7, 2013 and anther is the synthetic data (H3000) containing 3000 samples.

Validation results confirmed that 3-B and 4-B models have no significant advantages in freshwater chl-a estimation comparing to 2-B models. Fig. 10(a), (d), and (i) plot sampled against modeled chl-a concentrations for 2-B, 3-B, and 4-B band ratio algorithms, respectively. Mean RMSE values for 2-B models suggested from using in situ data and MERIS bands are 15.088 and 12.887. The corresponding RMSE values are 15.34 and 12.911 for 3-B models suggested from in situ and MERIS models, respectively. RMSE is 15.978 for 4-B model suggested from in situ data. The best performing model was the 2-B in situ MERIS model [Fig. 10(b), RMSE $=12.88$ ], which is slightly better than the 3-B in situ MERIS model [Fig. 10(e), RMSE = 12.91]. Similarly, the results from H3000 (Table III and Fig. 11) shown that over all, the 2-B models (mean RMSE $=13.00$ ) were better than the 3-B models (mean RMSE $=18.98$ ) and the 4-B did indeed perform the worst (mean RMSE $=38.68$ ). In fact, all of the validation results show that 2-B models consistently resulted in slightly smaller RMSE values. The 2-B models were the most robust with all $n / N$ ratios over $97 \%$. Related RMSE values are consistent to that from the model calibration and optimal band selection analysis.

Band ratio models derived from a synthetic data set with a wide range of chl-a concentrations worked very well for water environments with narrow chl-a concentration ranges. 
TABLE III

Validations for 2/3/4B chl-A Models Using In Situ Data on May 2013 and Synthetic Data Set H3000

\begin{tabular}{|c|c|c|c|c|c|c|c|c|}
\hline $\begin{array}{l}\text { Val. } \\
\text { Data }\end{array}$ & $\begin{array}{c}\text { Band } \\
\#\end{array}$ & Band used & $\begin{array}{c}\text { Calibration } \\
\text { data }\end{array}$ & $\begin{array}{l}n / N \\
\%\end{array}$ & MNB & MAE & $R^{2}$ & RMSE \\
\hline \multirow{16}{*}{ 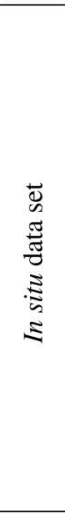 } & 2 & Suggested & In situ & 100 & 0.215 & 0.521 & 0.024 & 15.088 \\
\hline & 2 & MERIS & In situ & 100 & -0.018 & 0.381 & 0.596 & 12.877 \\
\hline & 2 & MODIS & In situ & 100 & -0.402 & 0.496 & 0.519 & 22.887 \\
\hline & 2 & Suggested & Synthetic & 100 & -0.345 & 0.442 & 0.343 & 18.676 \\
\hline & 2 & MERIS & Synthetic & 100 & 1.636 & 1.636 & 0.596 & 46.255 \\
\hline & \multirow[t]{2}{*}{2} & \multirow[t]{2}{*}{ MODIS } & \multirow{2}{*}{$\begin{array}{l}\text { Synthetic } \\
\text { Average }\end{array}$} & 100 & -0.32 & 0.377 & 0.533 & 17.058 \\
\hline & & & & 100 & 0.128 & 0.642 & 0.435 & 22.14 \\
\hline & 3 & Suggested & In situ & 100 & 0.127 & 0.507 & 0.001 & 15.34 \\
\hline & 3 & MERIS & In situ & 100 & -0.114 & 0.338 & 0.662 & 12.911 \\
\hline & 3 & Suggested & Synthetic & 76.923 & -0.609 & 0.609 & 0.679 & 26.454 \\
\hline & \multirow[t]{2}{*}{3} & \multirow[t]{2}{*}{ MERIS } & \multirow{2}{*}{$\begin{array}{l}\text { Synthetic } \\
\text { Average }\end{array}$} & 100 & 0.729 & 0.729 & 0.662 & 18.13 \\
\hline & & & & 94.231 & 0.033 & 0.546 & 0.501 & 18.209 \\
\hline & 4 & Suggested & In situ & 100 & 0.412 & 0.574 & 0.001 & 15.978 \\
\hline & 4 & Suggested & Synthetic & 100 & -0.471 & 0.482 & 0.750 & 21.686 \\
\hline & 4 & MERIS & Synthetic & 69.231 & -0.481 & 0.932 & 0.007 & 43.973 \\
\hline & & & Average & 89.744 & -0.18 & 0.662 & 0.253 & 27.212 \\
\hline \multirow{16}{*}{ 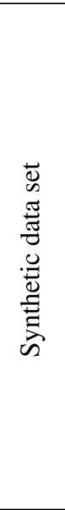 } & 2 & Suggested & In situ & 99.83 & -0.426 & 0.484 & 0.653 & 13.593 \\
\hline & 2 & MERIS & In situ & 100 & 0.942 & 1.151 & 0.812 & 12.056 \\
\hline & 2 & MODIS & In situ & 100 & 1.550 & 1.764 & 0.603 & 14.917 \\
\hline & 2 & Suggested & Synthetic & 99.87 & 2.309 & 2.342 & 0.589 & 14.649 \\
\hline & 2 & MERIS & Synthetic & 97.87 & 0.350 & 0.565 & 0.812 & 8.052 \\
\hline & \multirow[t]{2}{*}{2} & \multirow[t]{2}{*}{ MODIS } & \multirow{2}{*}{$\begin{array}{l}\text { Synthetic } \\
\text { Average }\end{array}$} & 99.90 & 2.367 & 2.392 & 0.605 & 14.750 \\
\hline & & & & 99.578 & 1.182 & 1.450 & 0.679 & 13.003 \\
\hline & 3 & Suggested & In situ & 19.67 & -2.597 & 2.600 & 0.362 & 24.446 \\
\hline & 3 & MERIS & In situ & 41.33 & -1.539 & 1.539 & 0.688 & 16.641 \\
\hline & 3 & Suggested & Synthetic & 100 & 3.942 & 3.944 & 0.718 & 23.004 \\
\hline & \multirow[t]{2}{*}{3} & \multirow{2}{*}{ MERIS } & Synthetic & 100 & 1.888 & 1.948 & 0.688 & 11.836 \\
\hline & & & Average & 65.250 & 0.424 & 2.508 & 0.614 & 18.982 \\
\hline & 4 & Suggested & In situ & 5.37 & -7.332 & 7.340 & 0.008 & 71.219 \\
\hline & 4 & Suggested & Synthetic & 100 & 3.552 & 3.575 & 0.432 & 20.198 \\
\hline & \multirow[t]{2}{*}{4} & \multirow{2}{*}{ MERIS } & \multirow{2}{*}{$\begin{array}{l}\text { Synthetic } \\
\text { Average }\end{array}$} & 99.97 & 4.038 & 4.042 & 0.523 & 24.610 \\
\hline & & & & 68.447 & 0.086 & 4.986 & 0.321 & 38.676 \\
\hline
\end{tabular}

The shadowed values are the best results from all multiband algorithms.

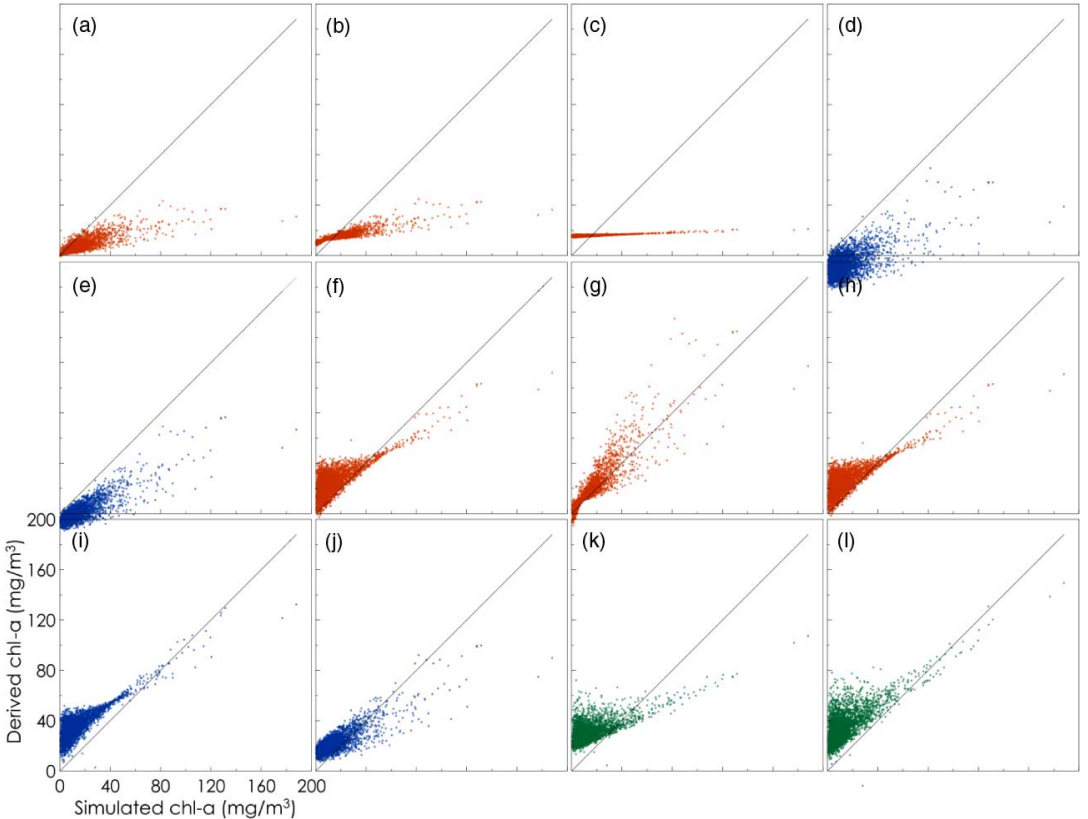

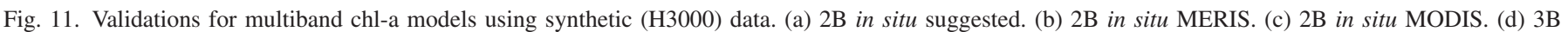

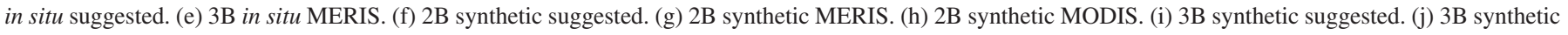
MERIS. (k) 4B synthetic suggested. (1) 4B in situ suggested.

The RMSE values from synthetic data validations are 18.676, 26.454, and 26.454 for 2-B, 3-B, and 4-B models, respectively. These values are much smaller than those $(56.59,55.56$, and 58.06) resulted in the model calibration phases (Table II). These smaller RMSE values from the synthetic validation efforts are due to the narrow range of chl-a concentrations 
$\left(0-184.84 \mathrm{mg} / \mathrm{m}^{3}\right.$ instead of $\left.0-1000 \mathrm{mg} / \mathrm{m}^{3}\right)$ in the validation synthetic data set. Models derived from synthetic data that inherently has a much wider range of chl-a concentration are more applicable across a broad range of environmental scenarios.

Band ratio models calibrated with the narrow range, in situ data of chl-a concentrations also worked satisfactorily for water environments with wide chl-a concentration ranges. Chl-a concentrations in the in situ data used for validation were ranged from $10 \mathrm{mg} / \mathrm{m}^{3}$ to $52 \mathrm{mg} / \mathrm{m}^{3}$ (see May 2013 data in Fig. 3), which is slightly broader range than those in the in situ data used for band and parameter calibrations $\left(5-45 \mathrm{mg} / \mathrm{m}^{3}\right)$. However, the RMSE values resulted in the validation are $15.088,15.34$, and 15.978, respectively, for $2-\mathrm{B}, 3-\mathrm{B}$ and 4-B models that are also satisfactory. The chl-a concentrations within $1.62-51.68 \mathrm{mg} / \mathrm{m}^{3}$ represent most of freshwater scenarios. Therefore, 2-B, 3-B, and 4-B models derived using in situ data are applicable to most freshwater cases.

\section{CONCLUSION}

This study demonstrated that using large set of synthetic data combined with in situ measurements is an effective approach of evaluating chl-a estimation algorithms. Typical advantages of synthetic data used in this study are the broad ranges of chl-a $\left(0.1-1000 \mathrm{mg} / \mathrm{m}^{3}\right)$, CDOM $\left(0-50 \mathrm{~m}^{-1}\right)$, and NAP $(0-500 \mathrm{mg} / \mathrm{l})$. Similarly, our in situ measurements from Lake Huron also have wide ranges of chl-a concentrations $\left(1.62-51.68 \mathrm{mg} / \mathrm{m}^{3}\right)$ and CDOM $\left(0.11-8.46 \mathrm{~m}^{-1}\right)$. An extremely wide range of chl-a concentrations $\left(0.1-1000 \mathrm{mg} / \mathrm{m}^{3}\right)$ in synthetic data set established the new models applicable across broad environmental conditions. The synthetic approaches (model analysis and data) can be widely applied to test scientific hypotheses in ocean optical science. The study had the following two scientific conclusions.

First, the study successfully tested the hypothesis that adding additional wavelength information to 2-B model could not make significant improvement in estimating freshwater chl-a, but acted to increase model uncertainty. This key result also answered Gurlin's question [29] that if a simple NIR-red twoband model are essential and sufficient for freshwater chl-a estimation. The reason of 2-B model performing better is that it is just simple and sufficient without involving further more uncertainty factors. The optimal wavelengths for 2-B model are red-NIR bands. When comparison is for using MERIS or MODIS images, the best two-band combination is the band 7 and band 9 of MERIS that performed better than those red-NIR bands of the MODIS.

Second, we introduced a set of new 2-B, 3-B, and 4-B models derived from using optimized parameters and band selection. These models were introduced in Sections III-E1 (2-B model), III-E2 (3-B) and III-E3 (4-B). The validation results demonstrated that these models are suitable to general freshwater environments because of broad ranges of biochemical and physical properties in both synthetic and in situ data. RMSE values from the evaluated algorithms are heavily influenced by the ranges of chl-a concentrations as displayed in Table II.
Thirdly, the study reveals that optimal hyperspectral wavelengths for individual models (2-B, 3-B, and 4-B) are subjective to the ranges of chl-a, CDOM, and NAP. The phenomena explain why previous case studies had resulted in controversial issues in band ratio chl-a algorithms. This phenomenon was confirmed by evaluating the performance of $34 \mathrm{chl}-\mathrm{a}$ algorithms with their original wavelengths and wavelengths suggested through optimization analysis. Parameter calibration are also associated with the uncertainty in remote sensing of chl-a.

\section{ACKNOWLEDGMENT}

The authors sincerely appreciate the constructive comments from anonymous reviewers. They also thank Dr. D. Learman for sharing the spectrophotometer in his laboratory for measuring CDOM absorption coefficients.

\section{REFERENCES}

[1] R. P. Bukata et al., Optical Properties and Remote Sensing of Inland and Coastal Waters. Boca Raton, FL, USA: CRC Press, 1995.

[2] R. L. Miller et al., Remote Sensing of Coastal Aquatic Environments: Technologies, Techniques, and Applications. New York, NY, USA: Springer, 2005.

[3] A. Morel and L. Prieur, "Analysis of variations in ocean color," Limnol. Oceanogr., vol. 22, pp. 709-722, 1977.

[4] H. R. Gordon and A. Morel, Remote Assessment of Ocean Color for Interpretation of Satellite Visible Imagery: A Review. Berlin, Germany: Springer-Verlag, 1983.

[5] J. E. O'Reilly et al., "Ocean color chlorophyll algorithms for SeaWiFS," J. Geophys. Res.-Oceans, vol. 103, pp. 24937-24953, 1998.

[6] G. Dall'Olmo et al., "Towards a unified approach for remote estimation of chlorophyll-a in both terrestrial vegetation and turbid productive waters," Geophys. Res. Lett., vol. 30, p. 1938, Sep. 2003.

[7] A. Gitelson, "The peak near $700 \mathrm{~nm}$ on radiance spectra of algae and water-Relationships of its magnitude and position with chlorophyll concentration," Int. J. Remote Sens., vol. 13, pp. 3367-3373, Nov. 1992.

[8] H. J. Gons, "Optical teledetection of chlorophyll a in turbid inland waters," Environ. Sci. Technol., vol. 33, pp. 1127-1132, Apr. 1999.

[9] S. J. Lavender et al., "SeaWiFS validation in European coastal waters using optical and bio-geochemical measurements," Int. J. Remote Sens., vol. 25, pp. 1481-1488, Apr. 2004.

[10] P. V. Zimba and A. Gitelson, "Remote estimation of chlorophyll concentration in hyper-eutrophic aquatic systems: Model tuning and accuracy optimization," Aquaculture, vol. 256, pp. 272-286, Jun. 2006.

[11] I. Dor and N. BenYosef, "Monitoring effluent quality in hypertrophic wastewater reservoirs using remote sensing," Water Sci. Technol., vol. 33, pp. 23-29, 1996.

[12] S. Sathyendranath, (Ed.), "Remote sensing of ocean colour in coastal, and other optically-complex, waters," Reports of the International OceanColour Coordinating Group, vol. 3. Dartmouth, Nova Scotia: IOCCG Project Office, 2000, p. 140.

[13] W. N. Zhu et al., "Estimation of chromophoric dissolved organic matter in the Mississippi and Atchafalaya river plume regions using abovesurface hyperspectral remote sensing," J. Geophys. Res.-Oceans, vol. 116, p. C02011, 2011.

[14] Q. Yu et al., "Functional linear analysis of in situ hyperspectral data for assessing CDOM in rivers," Photogramm. Eng. Remote Sens., vol. 76, pp. $1147-1158$, Oct. 2010

[15] L. H. Han and D. C. Rundquist, "Comparison of NIR/RED ratio and first derivative of reflectance in estimating algal-chlorophyll concentration: A case study in a turbid reservoir," Remote Sens. Environ., vol. 62, pp. 253-261, Dec. 1997.

[16] K. H. Mittenzwey et al., "Determination of chlorophyll-a of Inland waters on the basis of spectral reflectance," Limnol. Oceanogr., vol. 37, pp. 147149, Jan. 1992.

[17] A. A. Gitelson et al., "A simple semi-analytical model for remote estimation of chlorophyll-a in turbid waters: Validation," Remote Sens. Environ., vol. 112, pp. 3582-3593, Sep. 2008. 
[18] C. F. Le et al., "A four-band semi-analytical model for estimating chlorophyll a in highly turbid lakes: The case of Taihu Lake, China," Remote Sens. Environ., vol. 113, pp. 1175-1182, Jun. 2009.

[19] C. F. Le et al., "Remote estimation of chlorophyll a in optically complex waters based on optical classification," Remote Sens. Environ., vol. 115, pp. 725-737, Feb. 2011.

[20] G. Dall'Olmo and A. A. Gitelson, "Effect of bio-optical parameter variability on the remote estimation of chlorophyll-a concentration in turbid productive waters: Experimental results," Appl. Opt., vol. 44, pp. 3342-3342, Jun. 2005

[21] G. Dall'Olmo and A. A. Gitelson, "Effect of bio-optical parameter variability on the remote estimation of chlorophyll-a concentration in turbid productive waters: Experimental results," Appl. Opt., vol. 44, pp. 412-422, Jan. 2005.

[22] W. N. Zhu et al., "An assessment of remote sensing algorithms for colored dissolved organic matter in complex freshwater environments," Remote Sens. Environ., vol. 140, pp. 766-778, 2014.

[23] H. J. Carrick et al., "Wind influences phytoplankton biomass and composition in a shallow, productive lake," Limnol. Oceanogr., vol. 38, pp. 1179-1192, 1993.

[24] P. Vlahos et al., "Dissolved organic carbon in the Mid-Atlantic Bight," Deep-Sea Res. II. Topical Stud. Oceanogr., vol. 49, pp. 4369-4385, 2002.

[25] C. D. Mobley and L. K. Sundman, "Hydrolight 5 Ecolight 5 technical documentation," I. Sequoia Scientific, Ed., 2008.

[26] Z.-P. Lee, (Ed.), "Remote sensing of inherent optical properties: Fundamentals, tests of algorithms, and applications," Reports of the International Ocean-Colour Coordinating Group, No. 5, Dartmouth, Canada: IOCCG, 2006.

[27] L. Prieur and S. Sathyendranath, "An optical classification of coastal and oceanic waters based on the specific spectral absorption curves of phytoplankton pigments, dissolved organic-matter, and other particulate materials," Limnol. Oceanogr., vol. 26, pp. 671-689, 1981.

[28] W. N. Zhu et al., "An assessment of remote sensing algorithms for colored dissolved organic matter in complex fresh water environments," Remote Sens. Environ., vol. 140, pp. 766-778, 2014.

[29] D. Gurlin et al., "Remote estimation of chl-a concentration in turbid productive waters-Return to a simple two-band NIR-red model?" Remote Sens. Environ., vol. 115, pp. 3479-3490, Dec. 2011.

[30] G. Dall'Olmo and A. A. Gitelson, "Effect of bio-optical parameter variability and uncertainties in reflectance measurements on the remote estimation of chlorophyll-a concentration in turbid productive waters: Modeling results," Appl. Opt., vol. 45, pp. 3577-3592, May 2006.

[31] C. F. Le et al., "Evaluation of chlorophyll-a remote sensing algorithms for an optically complex estuary," Remote Sens. Environ., vol. 129, pp. 75-89, Feb. 2013.

[32] V. E. Brando and A. G. Dekker, "Satellite hyperspectral remote sensing for estimating estuarine and coastal water quality," IEEE Trans. Geosci. Remote Sens., vol. 41, no. 6, pp. 1378-1387, Jun. 2003.

[33] A. A. Gitelson, et al., "Remote chlorophyll-a retrieval in turbid, productive estuaries: Chesapeake Bay case study," Remote Sens. Environ., vol. 109, pp. 464-472, 2007.

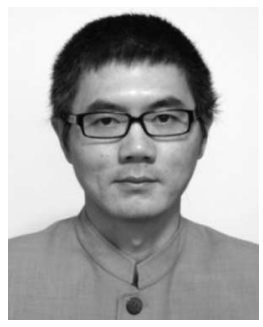

Weining Zhu received the Ph.D. degree in geosciences from the University of Massachusetts, Amherst, MA, USA, in 2012.

He was with the Institute for Great Lakes Research and the Department of Geography, Central Michigan University Mt. Pleasant, MI, USA, from 2012 to 2013. He is currently an Associate Professor with the Department of Ocean Science, Ocean College, Zhejiang University, Hangzhou, China. His research interests include ocean color, ocean optics, hyperspectral remote sensing, and GIS spatial analysis.

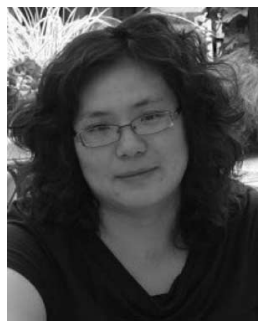

Qian Yu received the B.S. and M.S. degrees in geography from Nanjing University, Nanjing, China, in 1999 and 2001, respectively, and the Ph.D. degree from the University of California, Berkeley, CA, USA, in 2005.

Since 2006, she has been a Faculty Member with the Department of Geosciences, University of Massachusetts, Amherst, MA, USA. Her research interests include hyperspectral and highresolution remote sensing of vegetation and water biogeochemistry.

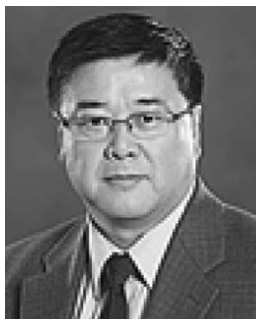

Yong Q. Tian received the B.S. degree in mathematics from Shanxi University, Taiyuan, China, and the M.S. and Ph.D. degrees in computer science from the University of Newcastle upon-Tyne, NE, U.K., and the University of Waikato, Hamilton, New Zealand, in 1981, 1989, and 1995, respectively.

He was a Scientist with the National Institute of Water and Atmospheric Research and National Institute of Agricultural Research, New Zealand, from 1995 to 2000. He was an Assistant Specialist with the Department of Environmental Science, Policy, and Management with the UC Berkeley, CA, USA, from 2000 to 2003, and a Faculty Member with the University of Massachusetts, Boston, MA, USA, from 2003 to 2011. Since 2011, he has been an Associate Professor, a cohort of faculty with specializations relevant to Great Lakes Research with Central Michigan University, Mt. Pleasant, MI, USA. His research interests include GIS and remote sensing and coastal ecological modeling and analysis.

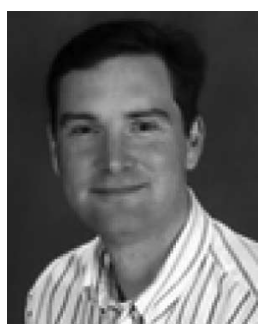

Brian L. Becker received the B.S. degree in botany/environmental science from Eastern Illinois University, Charleston, IL, USA, in 1990, the M.S. degree in civil engineering/environmental science from the University of Illinois, Champaign, IL, USA, in 1993, and the Ph.D. degree in geography/remote sensing from Michigan State University, East Lansing, MI, USA, in 2002.

Since 2002, he has been with the Department of Geography, Central Michigan University, Mt Pleasant, MI, USA. His research interests include hyperspectral/high-resolution remote sensing of wetland vegetation and Great Lakes water biogeochemistry.

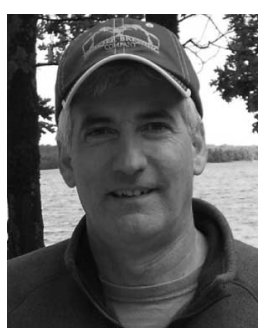

Hunter Carrick received the B.S. degree in biological sciences from Binghamton University, New York, NY, USA, in 1983, the M.S. degree in aquatic ecology from Bowling Green State University, OH, USA in 1985, and the Ph.D. degree from the University of Michigan, Ann Arbor, MI, USA, in 1990

He was a Postdoctoral Fellow with the University of Florida, Gainesville, FL, USA from 1990 to 1992. He was a Faculty Member with Pennsylvania State University, University Park, PA, USA from 2011 to 2011. He is currently a Professor with the Department of Biology, Central Michigan University, Mt. Pleasant, USA. His research interests include linking phytoplankton abundance and taxonomic composition with changes in the biogeochemistry of large lakes and rivers. 